\title{
APPLICATION OF FREQUENCY AND TIME DOMAIN INDUCED POLARIZATION - RESISTIVITY EFFECTS FOR EXPLORING AQUIFER AND HYDROCARBON RESERVOIRS IN BAHIA, BRAZIL
}

\author{
Olivar A. L. de Lima and Hédison K. Sato
}

\begin{abstract}
Two field surveys using the induced polarization (IP) - resistivity method, are presented as an effective tool to evaluate aquifer and hydrocarbon reservoirs at shallow depths. First, the electrochemical mechanisms responsible for generating IP effects in reservoir rocks are reviewed. Then, theoretical developments are proposed to reduce the inductive electromagnetic coupling from the underground IP effects, and to compute three fundamental electrical parameters, namely the apparent DC-resistivity, the apparent chargeability and relaxation time, both for frequency (FD) and time domain (TD) data. These parameters are attributed to average representative volumes of the subsurface geology, which depends on the electrode array and its characteristic depth of investigation. The studied structure includes: an upper fresh-water sandstone aquifer of 60m average thickness; overlaying a 70m thick, prismatic sandstone oil-reservoir, sandwiched between shale sequences and laterally confined by intersecting normal faults. The data acquisitions were made using dipole-dipole electrode arrays, with lengths a of 50 and $100 \mathrm{~m}$, and separations $n$ a, with $n$ ranging from 1 to 12 (FD), and 1 to 6 (TD). The 2-D inverted pseudo-sections exhibit small distortions, attributed to differences in resolution, terrain effects and signal-to-noise ratios, but are consistent in outlining the following features: i) the detection of an upper resistive low IP layer, representing a water-table aquifer; ii) a distinct electrical anomaly, related to the western bounding fault zone, depicted as a conductive chimney bordered by high resistive halos; iii) the separation of different geo-electrical units within the shale sequence sealing the reservoir; and iv) the delineation of the top of oil reservoir, defined by a slight increase in resistivity and by high IP values, at and above the oil reservoir.
\end{abstract}

Keywords: electrical resistivity, induced polarization, aquifers, oil reservoirs.

RESUMO. Levantamentos geofísicos usando resistividade e polarização induzida (PI) são apresentados como uma ferramenta eficaz para avaliar aquíferos e reservatórios petrolíferos em profundidades rasas. Primeiro, faz-se uma revisão dos mecanismos eletroquímicos geradores de Pl em rochas reservatórios. Em seguida, propõem-se tratamentos teóricos para separar o acoplamento eletromagnético dos efeitos puros da PI subterrânea e calcular três parâmetros aparentes fundamentais: resistividade $\left(\rho_{0, a}\right)$, cargabilidade $\left(m_{w, a}\right)$ e tempo de relação $\left(\tau_{w, a}\right)$, tanto no domínio da frequência (FD) quanto do tempo (TD). Esses parâmetros são atribuídos a centros volumétricos representativos da geologia, que dependem do arranjo de eletrodos e de suas profundidades de investigação. A estrutura estudada inclui: um aquífero arenoso superior, com 60m de espessura; sobreposto a um reservatório petrolífero prismático de arenitos, com 70m de espessura, intercalado entre sequências argilosas, e lateralmente confinado por falhas normais intercruzadas. Os dados foram adquiridos com arranjos dipolo-dipolo usando distâncias entre eletrodos de $50 \mathrm{e}$ 100 m, e separações na, com n variando de 1 a 12 (FD) e 1 a 6 (TD). As seções 2-D invertidas exibem pequenas distorções, atribuídas a diferenças de resolução, efeitos de terreno e razão sinal-ruído, mas consistentes na identificação dos seguintes aspectos: (i) detecção de camada superior resistiva e baixo PI, representando 0 aquífero freático; (ii) anomalia elétrica relacionada à falha do limite ocidental, revelada como uma chaminé condutora com halos de maior resistividade; (iii) separação de duas unidades geoelétricas na sequência dos folhelhos selantes do reservatório; e (iv) delineamento do topo do reservatório de óleo, definido por um ligeiro aumento na resistividade e por altos valores de PI no e acima do reservatório.

Palavras-chave: resistividade elétrica, polarização induzida, aquíferos, reservatórios.

Corresponding author: Olivar A. L. de Lima

Universidade Federal da Bahia, Center for Research in Geophysics and Geology (UFBA/CPGG), Geosciences Institute, Rua Barão de Jeremoabo, s/n, Campus Universitário de Ondina-40.170-290, Salvador, BA, Brazil --E-mails: olivar@ufba.br, sato@ufba.br 


\section{INTRODUCTION}

The electrical resistivity - induced polarization method has played an important role in the exploratory efforts to discover mineral deposits in the Precambrian terrains of North America, Europe, Australia and Brazil (Bleil, 1953; Seigel, 1959; Sumi, 1961; Pelton et al., 1978; Palacky, 1987; Collett, 1990). The initial works were focused on its physical basis and on the development of field instrumentation. Others were concerned with theoretical and experimental aspects involved with the assessment and description of the electrochemical mechanisms generating IP phenomena in rocks (Vacquier et al., 1957; Wait, 1959; Marshall \& Madden, 1959; Madden \& Cantwell, 1967; Dias, 1972; Zonge \& Wynn, 1975; Collett, 1990).

The success of electrical (EL) and electromagnetic (EM) applications in oil exploration, measuring IP and resistivity, are attributed to the following factors: i) their high sensitive to changes in geologic materials, caused either by diagenetic and structural alterations, or by redistribution of fluids in pores and fractures of the reservoir, after migration or during the production history of an oil field (Spies, 1983; Keller et al., 1984; Dias et al., 2007; Zhangxiang et al., 2010); ii) the depth of investigation and the resolution of the measurements were improved with modern controlled-source EM systems (Zhdanov, 2010; Barker et al., 2012); and iii) the reduction of unwanted distortions caused by geological and cultural noises through the use of computational procedures, such as automatic stacking, numerical filtering and coherence signal analysis (Dias et al., 2007; Streich et al., 2011; Barker et al., 2012).

The present work is part of a research project conducted by the Center for Research in Geophysics and Geology from the Universidade Federal da Bahia (CPGG/UFBA) in cooperation with Petróleo Brasileiro S. A. (PETROBRAS), which aims to test the use of EL\&EM methods in the exploration and production of oil fields. Its main objectives are to review the basic aspects of the induced polarization phenomena in rocks, emphasizing on the source development, data analysis to separate EM coupling from electrochemical effects, and their application to the direct detection and delineation of aquifers and oil reservoirs in onshore sedimentary basins.

The fieldwork was performed over a producing structural oil field within the Recôncavo sedimentary basin, an important oil province in Bahia state, Brazil. Two experimental setups and different instrumentation were employed: i) one $1.9 \mathrm{~km}$ extent FD tomographic transverse was surveyed with System 2000. net equipment from Phoenix Geophysics operating under the spectral
IP mode (FD-SIP), using a dipole length $a=100 \mathrm{~m}$ and $n a$ separation from 100 to $1200 \mathrm{~m}$. Its main purpose was to outline an upper water-table sandstone aquifer, and a $70 \mathrm{~m}$ thick, dipping prismatic oil-sandstone reservoir, confined between thick shale sequences, and laterally bounded by subvertical normal faults; ii) another TD dipole-dipole section, covering the initial $1200 \mathrm{~m}$ portion of the same line, using a VIP transmitter 3000 and ELREC Pro receiver from Iris Instruments. The TD work had the main purpose to detail the geometry of the upper aquifer structure, using the same array acquisition at two dipole lengths $(a=50$ and $100 \mathrm{~m}$ ) and $n$ ranging from 1 to 6 , represented along the same IP-resistivity cross-sections.

\section{THE IP PHENOMENON}

Since its early history, the IP-resistivity method has been widely applied for exploration of disseminated metallic mineral deposits (Zonge \& Wynn, 1975; Pelton \& Smith, 1976). The method has also been successfully applied for the environmental and geotechnical characterization of the subsurface geology near urban areas (Börner et al., 1993; Kemna et al., 2004; Boadu \& Seabrook, 2006; Boadu \& Owusu-Nimo, 2010). More recently, the method has started to be used in hydrocarbon exploration (Zhangxiang et al., 2005; Davydycheva et al., 2006; Zhangxiang et al., 2007; Dias et al., 2012).

The method can be operated in frequency or time domain. In the frequency domain (FD), the variation in the complex apparent resistivity of the ground is measured as a function of the frequency of an external current source. In the time domain (TD), the phenomenon is observed as a relaxation of a secondary voltage present in the ground, after the interruption of the primary current source.

Basically, the IP phenomenon in geological materials is determined by distributed mineralogical sources acting as ionic-charge separators. These effects are pronounced at the interfaces between metallic or membrane-filtering particles, and the pore-water electrolyte of rocks. Non-uniform charge distributions around mineral grains are developed in response to diffusive ionic fluxes and to active chemical reactions, involving charge transfer between solids and fluid. Such combined electrochemical phenomena are termed interfacial polarization (Marshall \& Madden, 1959; Dukhin \& Shilov, 1974; Lima \& Sharma, 1992).

\section{IP Sources in Rocks}

An appreciable amount of electrical measurements made on rock specimens and outcrops show that the electrical resistivity is 
frequency dependent or dispersive. At low frequencies (in the range from $0.1 \mathrm{~Hz}$ to $1.0 \mathrm{MHz}$ ), its amplitude decreases smoothly with the angular frequency $\omega$, up to a constant value that is higher than half of its DC-value (Vinegar \& Waxman, 1984; Lesmes \& Frye, 2001; Scott \& Barker, 2003). These features result both from microstructural and textural aspects of the rocks, which determine the combination of the electrical properties of their constituents, and from electrochemical effects at the interfaces between minerals and the pore-space solution (Marshall \& Madden, 1959; Lima \& Sharma, 1992; Dias, 2000).

On the solution side of any grain-water interface within a heterogeneous porous rock a double-layer structure of electrical charges develops naturally. The grain or crystal composition and morphology, the salinity of the pore-water and the physical/chemical conditions of the underground environment control the behavior of this structure.

When an external alternating electrical field is applied to such a heterogeneous mixture, the ionic double-layers are distorted and the ionic fluxes to or from an interface will generate excesses and deficiencies of ionic species on opposite sides of the source mineral. Thus, a dynamic microscopic distribution of electrical dipoles oriented in opposition to the applied field is established (Seigel, 1959; Lima \& Sharma, 1992; Dias, 2000).

Although this situation holds for any rock material, these effects are particularly significant when the rock contains disseminated metallic minerals, distributed clays or clay-coated grains, or highly contrasting dielectric materials. The charge separation along them is controlled by the geometry of the interface and by the double-layer structure around the particles, in addition to the electric field oscillating character. On basis of the source elements, the IP is normally classified as electrode (or metallic) polarization and membrane (or clay) polarization (Bertin \& Loeb, 1976; Angoran \& Madden, 1977; Wong, 1979).

The electrode polarization is developed at interfaces between metallic minerals (pyrite, chalcopyrite, magnetite, etc.), where conduction takes place by electron transport, and the electrolytic pore-solution, where conduction is predominantly ionic (Marshall \& Madden, 1959; Slater et al., 2006; Ishai et al., 2013). Membrane polarization occurs at interfaces between regions of different ionic transport restrictions, related to clay minerals distributed in the rock matrix (Angoran \& Madden, 1977; Wong, 1979; Lima \& Sharma, 1992).

In the case of electrode polarization, the metallic grains and their ionic double-layers act as barriers to the ionic fluxes within the solution and to electron transport inside the minerals. Due to redox reactions at the interface, a carrier exchange from ions to electrons may also occur across the interface. When an electrical current is established in the rock, most of it will flow through the pore-space solution. In the vicinity of a metallic grain, the flow is distorted, causing more current to flow near and through the metallic particle. At the interface, this flow delivers and removes ionic particles from the solution. Thus, a disseminated distribution of metallic grains has a net macroscopic effect that manifest itself as a complex impedance.

This complex impedance depends on the electrochemical reaction rates, the diffusive transport rate of the reactive ions and the volumetric proportion of metallic particles disseminated in the solid matrix. The essential features of these processes are sketched in Figure 1a, in terms of averaged current lines and zones of charge accumulation around the metallic minerals. Several authors have shown that this impedance, known as Warburg impedance, has a primary component whose magnitude is inversely proportional to the concentration of reacting species and to the square root of the frequency of the oscillating field $\left(Z_{w} \propto(i \omega)^{-1 / 2}\right)$ (Marshall \& Madden, 1959; Dias, 1972; Angoran \& Madden, 1977; Wong, 1979).

In the case of clay membranes in shaly-sandstones, the ionic blockages are especially concentrated at the pore throats, where membrane filtration effects are more effective (Fig. 1b). The electrical double-layers surrounding the pore-throat walls allow the passage of cations but restrict the passage of anions. In dilute solutions, the transport paths of the clay counter-ions are preferably located inside the clay shells coating the sand grains. Because anions and cations do not move independently, membrane potentials may also be imposed between the free solution in the pore bodies and that in the clay shells (Lima \& Sharma, 1992; Revil, 1999).

Clay platelets are assumed to uniformly coat a sandstone channel wall. Under the absence of an external electric field, its cationic double-layer compensates the charges on the clay surfaces. Under the action of an electric field, the channeled current component will develop differential ionic fluxes inside the channels and around the coated grains (Fig. 1b). However, the cationic selectivity of clays in a channel constriction will oppose the transfer of anions. These barrier effects will change the ionic distribution within the pore-space. A cationic depletion is induced on one side of a grain and a concentration of the same species is created on the other side, with the reversed situation for the anions. Under a sustained DC-current, an equilibrium condition is attained, and the concentration difference is mainly determined 


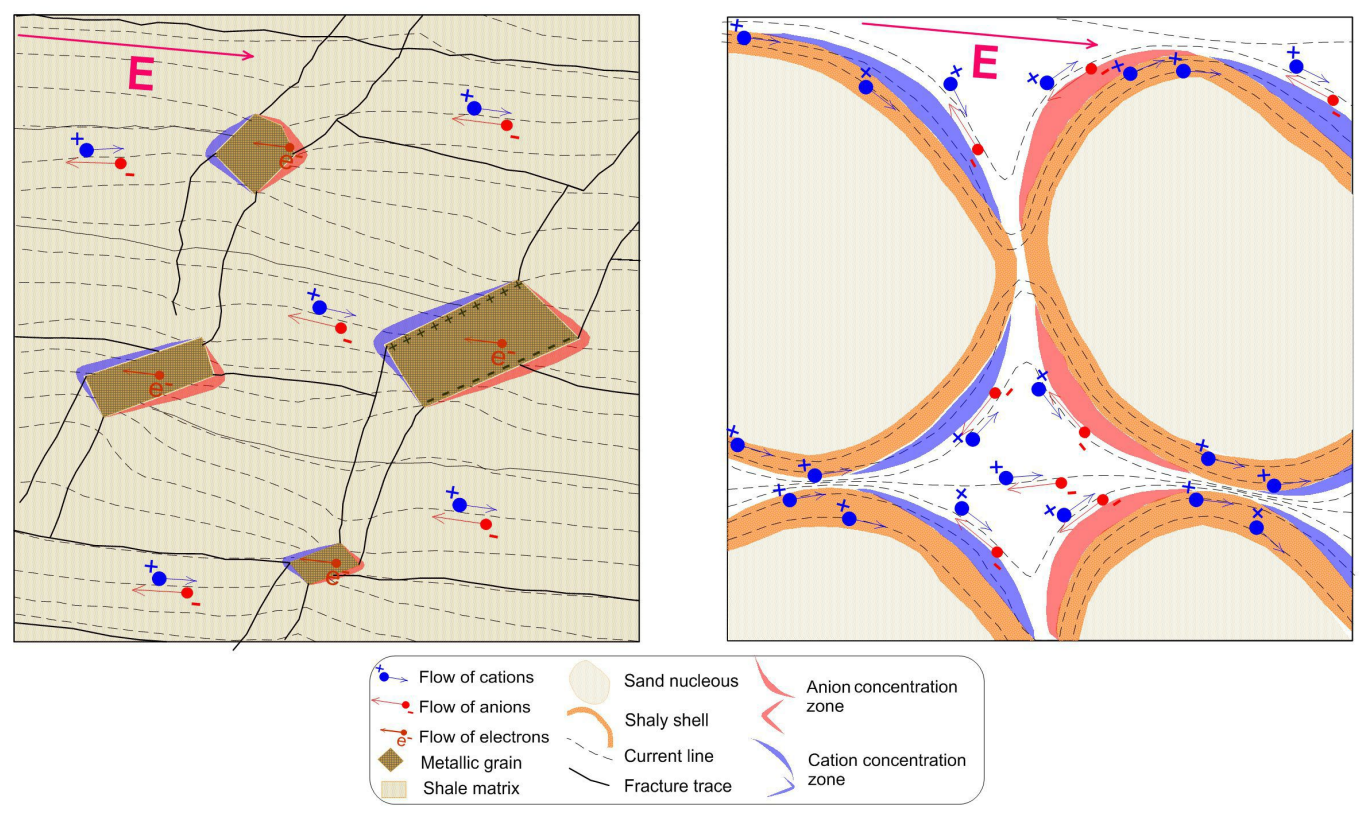

a) Electrode polarization

b) Membrane polarization

Figure 1 - Schematic representation of the main microstructural and textural elements responsible for the generation of IP effects in rocks.

by the perm-selectivity of the clays, the electrolyte concentration, the coefficient of ionic diffusion and the magnitude of the applied field (Dukhin \& Shilov, 1974; Revil, 1999).

Figures 1a and $1 \mathrm{~b}$ depict the main microscopic features resulting from the described processes. For simplicity, only a few characteristic current lines are outlined, along with their dominant ionic pathways. The complex impedance related to these mechanisms has been shown to be dependent of a diffusive relaxation process operating around the coated sand grain structure, and under the control of the electrical double-layer around a coated sand grain (Dukhin \& Shilov, 1974; Lima \& Sharma, 1992).

In the microscopic illustrations of Figure 1, the thicknesses of the zones of excess cation and anion concentrations and the ion sizes were exaggerated to highlight the macroscopic presence of a volumetric distribution of electrical dipoles created by the applied electric field.

\section{IP Effects and Oil Fields}

Two stages in the geological evolution of a sedimentary basin are responsible for oil reservoir accumulation and the mineralogical transformations that may create disseminated IP sources around them, making their detection possible with EL\&EM methods: i) the mechanical compaction and the diagenetic alterations of the sedimentary package, which occur during the cyclic alternation between subsidence and uplift of the basin, under strong tectonic and geothermal regimes; and ii) the mineralogical transformations during the final uplift and erosion of a compacted sedimentary fill under more stable, low tectonic influences (Bjorlykke, 1988; Morad et al., 2000; Ketzer, 2002).

The spatial and temporal patterns in the distribution of diagenetic alterations in sedimentary sequences result from the combined action of a series of complex interrelated factors (Bjorlykke, 1988; Ketzer, 2002; Lucia, 2004): a) the depositional environment, the initial lithological composition and the tectonic setting; b) the geothermal gradient, the subsurface pressure and the tectonic stress; c) the time-depth history of burial and uplift and the thermal residence-time under stable geologic conditions; and d) the subsurface water flow patterns, the chemistry of the interstitial water, and the hydrocarbon maturation and migration in time.

In siliciclastic sequences, the main diagenetic alterations include compaction and porosity reduction; mechanical infiltration of clays into sandstones; formation of authigenic clay minerals, carbonate cement, feldspar and quartz overgrowths; and the precipitation of pyrite concretions and of other metallic compounds caused by rock-fluid interactions that are enhanced by organic matter and microbial activity (Brothers et al., 1996; 
Morad et al., 2000). The amount of metallic minerals so formed may range from less than $1 \%$ up to almost $10 \%$ of the total solids, as estimated by several authors (Surdam et al., 1989; Ketzer, 2002).

These alterations are mostly developed in the early to middle stage of diagenesis, where mechanical compaction of the sedimentary fill promotes a grain rearrangement and the vertical ejection of large quantities of mineralized water and other fluids. The hydrothermal fluids with hydrocarbons migrate upwards to the sandstone-rich sections. This primary vertical seepage may be enhanced or modified along fault zones and bedding planes within coarse lithologies (Bjorlykke, 1988; Surdam et al., 1989; Ketzer, 2002).

After the formation of a hydrocarbon reservoir, some quantity of light hydrocarbons may leak and seep upward to the surface. These seeps lead to a reduced zone well above the reservoir due to bacterial activity, even if this zone was previously oxidized. Such reduced conditions can result in the precipitation of additional disseminated metallic minerals (primarily pyrite and magnetite). This type of alteration above oil reservoirs has been detected by induced polarization surveys (Sternberg, 1991).

Based on the described evolution, Figure 2 summarizes the main geological alteration zones developed around a structural fault-controlled hydrocarbon reservoir typical of the Recôncavo sedimentary basin. In fact, the sketched geological structure represents the studied reservoir, and its main lithological units. The outlined diagenetic zones were defined according to geological and geophysical well log data supplied by Petrobras.

\section{EXTRACTING THE EM COUPLING EFFECTS}

An important aspect related to the IP measurements is the distinction between the complex resistivity variation with frequency (electrochemical effect) and the changes caused by the inductive electromagnetic coupling between the electrical circuits and the underground geology. The former effect is generally described as a Debye relaxation phenomenon (Pelton et al., 1978; Binley \& Kemna, 2005). This theme has been the subject of many studies and several de-coupling processes have been devised (Hohmann, 1973; Pelton et al., 1978; Coggon, 1984; Johnson, 1990). Some were theoretically well supported, but difficult for practical application. Here we develop two simple algorithms, based on the correspondence to a homogeneous and isotropic half-space of complex resistivity $\rho^{*}(\omega)$, for de-coupling both FD and TD IP-resistivity data.

The physical basis or assumptions for the procedures are as follows: i) the EM coupling and the IP effects are the superposition of two distinct processes, dominating different portions of the frequency or time spectra used in the acquisition. This hypothesis is supported by the works of Wait \& Gruszka (1986) for FD data, and of Johnson (1990) for TD data; ii) the complex apparent resistivity values derived from the measurements, in the range of fitting to the IP effects, are described by a relationship derived for the complex resistivity of a rock sample, or of a polarizable homogeneous terrain. This implies that the responses to be fitted comes from a defined volume of the subsurface, in which the apparent resistivity and chargeability, $\rho_{a}, m_{a}$, changes are essentially due to frequency or time, but not on the T-R array and spacing; iii) the function-adjusted apparent parameters are assigned to the centers of representative underground volumes, at $x, z$ coordinates dependent on the T-R geometry and the distance between them. This assumption is justified by the success in representing EL\&EM responses as 1-D or 2-D pseudo-section.

\section{FREQUENCY DOMAIN}

The complex resistivity $\left(\rho^{*}\right)$ of a homogeneous, isotropic and polarizable material may be written in the following forms:

$$
\rho^{*}(\omega)=\rho_{R}+i \rho_{I}=\left|\rho^{*}\right| e^{i \varphi},
$$

where $\rho_{R}, \rho_{I}$ are its real and imaginary parts, $\mid \rho^{*} /$ the amplitude and $\varphi$ the phase of the complex function. Furthermore,

$$
\left|\rho^{*}\right|=\left(\rho_{R}^{2}+\rho_{I}^{2}\right)^{1 / 2},
$$

and

$$
\varphi=\tan ^{-1} \frac{\rho_{I}}{\rho_{R}} .
$$

For an in-line dipole-dipole array, the mutual impedance sensed above a homogeneous, polarizable ground is given by (Wait \& Gruszka, 1986)

$$
\begin{gathered}
Z(\omega)=\frac{\rho^{*}(\omega) k}{4 \pi}\left\{\frac{2}{n(n+1)(n+2) a k}-\right. \\
-2 G[(n+1) a k]+G(n a k)+G[(n+2) a k]\},
\end{gathered}
$$

where $k$ is the wave number $(k=\sqrt{i \mu \sigma \omega}$, $a$ is the dipole length, and na the separations between transmitter and receiver dipoles. The function $G(z)$ is defined by

$$
G(z)=\left(\frac{1}{z}-1\right) e^{-z}+z \int_{z}^{\infty} \frac{e^{-v}}{v} d v .
$$

where $z$ is a complex argument given between brackets in Eq. (4), and $v$ the integration variable.

Expression (4) may be interpreted as composed of two main contributions, one attributed to the galvanic coupling, and 


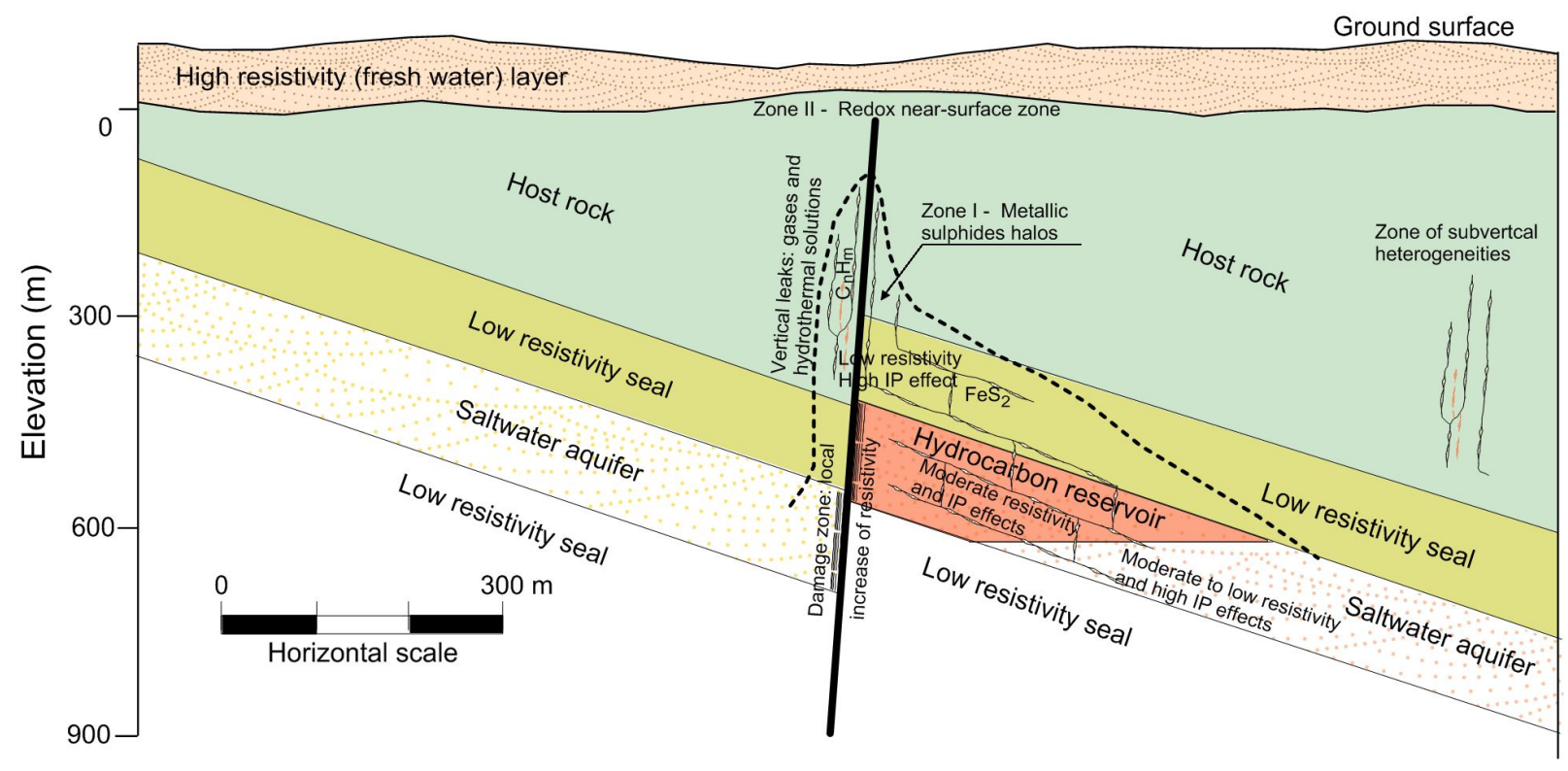

Figure 2 - Geological depth-section showing the main litho-structural features and diagenetic zones that generate strong IP effects above underground oil reservoirs.

another due to inductive effects. In the limiting case as $\omega \rightarrow 0$, Eq. (4) reduces to

$$
Z_{0}=\frac{\rho_{0}}{\pi n(n+1)(n+2) a},
$$

where $\rho_{0}$ is the medium DC-resistivity value.

Equation (6) is used as an effective approximation for computing the amplitude and phase of the complex apparent resistivity function for a dipole-dipole array, at a given frequency, via the following equations

$$
\begin{gathered}
\left|\rho_{\mathrm{a}}(\omega)\right|=|\mathrm{Z}(\omega)|[\pi \mathrm{n}(\mathrm{n}+1)(\mathrm{n}+2) \mathrm{a}]=\mathrm{K}_{d d}\left|\frac{\Delta \mathrm{V}}{\mathrm{I}}\right|, \\
\varphi_{\rho_{a}}=\varphi_{Z}=\varphi_{\Delta V}-\varphi_{I} .
\end{gathered}
$$

where $\varphi_{\Delta V}$ and $\varphi_{I}$ are, respectively, the phase voltage in the receiver and of the current recorded in the transmitter, and $K_{d d}$ the geometric factor for the dipole-dipole array.

To describe the complex resistivity of a homogeneous ground we adopted the analytical model proposed by Dias (1972; 2000). Based on his circuital model, we devise a practical procedure to approximately extract the IP effects in SIP field data. The complex resistivity function for such model is expressed as

$$
\rho^{*}(\omega)=\rho_{0}\left\{1-m\left[1-\frac{1}{1+i \omega \tau^{\prime}\left(1+\frac{1}{\mu}\right)}\right]\right\},
$$

where $m$ is the chargeability, a parameter representing the magnitude of the electrical polarization effect and defined by Seigel (1959) as $m_{w}=\left(\rho_{0}-\rho_{\infty}\right) / \rho_{0}$. The parameter $\tau$ ' is the relaxation time for the polarization, i $\mu$ is a complex parameter ( $\mu=i \omega \tau+\sqrt{i \omega \tau}$ ), with $\tau$ and $\tau$ " as two additional relaxation times used by Dias (1972) to explain the whole dispersion with frequency.

Recently, Barreto \& Dias (2014), using Heaviside's theorem for the ratio of two polynomials of the same variable, performed a decomposition of Eq. (9) into three partial fractions. Based on this decomposition Eq. (9) was rewritten as

$$
\begin{array}{r}
\rho^{*}(\omega)-\rho_{\infty}=\rho_{0}\left(\frac{m_{w}}{1+\left(i \omega \tau_{w}\right)^{\frac{1}{2}}}+\right. \\
\left.+\frac{m_{d} \vartheta_{a}\left[\left(i \omega \tau_{d}\right)^{1 / 2}-\vartheta_{b}\right]}{1+\left[\left(i \omega \tau_{d}\right)^{\frac{1}{2}}-\vartheta_{b}\right]^{2}}+\frac{m_{d}}{1+\left[1+\left(i \omega \tau_{d}\right)^{\frac{1}{2}}-\vartheta_{b}\right]^{2}}\right),
\end{array}
$$

with $\tau_{w}=\left[\left(\tau+\tau^{\prime}\right) / \varepsilon \tau\right]^{2}, \tau_{d}=\tau \tau^{\prime} /(\tau+\tau), m_{w}=m \tau_{w} / \tau^{\prime}$, and $m_{d}=m \tau_{d} / \tau$. Parameters $\vartheta_{a}$ and $\vartheta_{b}$ are dependent on the roots and coefficients of the decomposition (For details see Barreto \& Dias, 2014).

According to Barreto \& Dias (2014), each term in Eq. (10) is related to a different dispersion mechanism acting to compose the complex resistivity spectrum: i) the first is basically attributable to the relaxation of the polarization, caused by ionic diffusion around dispersed particles, causing IP and acting mainly in the low frequency range $(f<100 \mathrm{~Hz})$; ii) the second is a transitional 
regime, represented by the combination of conduction and diffusion processes that occurs at intermediate frequencies (100 $\mathrm{Hz}$ to $1.0 \mathrm{kHz}$ ); iii) the third, expressed as a Debye polarization, is primarily related to capacitive effects developed around the source grains and occurs predominantly at high frequencies (>1 $\mathrm{kHz}$ ). Thus, for most rocks the two last terms of Eq. (10) are essentially manifested above $100 \mathrm{~Hz}$. At this range, these terms are intricately combined with inductive EM coupling, rendering the distinction between the electrochemical polarization effects and the effects of EM coupling difficult or impossible. Thus, only the first and principal term of Eq. (10) should be used as the sole representative term of the IP effects, which produces the following simplified equation

$$
\rho(\omega)=\rho_{0}\left\{1-m_{w}\left[1-\frac{1}{1+\left(i \omega \tau_{w}\right)^{1 / 2}}\right]\right\}
$$

with $m_{w}$ representing the pure electrochemical chargeability and $\tau_{w}$ the relaxation time for this polarization. The time-constant $\tau_{w}$ has been shown to be dependent on the grain-size diameter and on the ionic diffusion coefficient through the rock pores (Dukhin \& Shilov, 1974; Lima \& Sharma, 1992; Barreto \& Dias, 2014).

For the EM coupling reduction, we may use either the real and imaginary parts or the amplitude and phase of the simplified complex resistivity function given by Eq. (11). The expressions for such components are explicitly computed from the following algebraic equations

$$
\rho_{R}(\omega)=\frac{\rho_{0}\left[1+\left(2-m_{w}\right) \sqrt{\omega \tau_{w} / 2}+\left(1-m_{w}\right) \omega \tau_{w}\right]}{1+\sqrt{2 \omega \tau_{w}}+\omega \tau_{w}},
$$

and

$$
\rho_{I}^{*}(\omega)=\frac{\rho_{0} m_{w} \sqrt{\omega \tau_{w} / 2}}{1+\omega \tau_{w}+2 \sqrt{\omega \tau_{w} / 2}}
$$

or

$$
\left|\rho^{*}\right|=\frac{\rho_{0}\left\{\left[1+\left(2-m_{w}\right) \sqrt{\omega \tau_{w} / 2}+\left(1-m_{w}\right) \omega \tau_{w}\right]^{2}+m_{w}^{2} \omega \tau_{w} / 2\right\}}{1 \pm \sqrt{2 \omega \tau_{w} / 2}+\omega \tau_{w}},
$$

and

$$
\varphi=\frac{m_{w} \sqrt{\omega \tau_{w} / 2}}{1+\left(1-m_{w}\right) \omega \tau_{w}+\left(2-m_{w}\right) \sqrt{\omega \tau_{w} / 2}}
$$

Expressions (12) to (15) may be used to describe experimental laboratory data and to model electrical soundings and tomographic pseudo-sections. For interpretation purposes they must be used, under the specified assumptions, to compute $\rho_{0, a}, m_{w, a}$ and $\tau_{w, a}$ through a best fit procedure to experimental field data. A basic requirement is that the effective sampled volume searched at a given sounding, in the low frequency range of the used spectrum, changes little with frequency. Under this condition $\rho_{o, a}$ is inferred from the low frequency behavior of the real part or amplitude of $\rho^{*}$, and $\tau_{w, a}$ from the pick of its phase distribution.

For a homogenous half-space the amplitude of $\rho^{*}(\omega)$ expressed by Eq. (7) (with $Z(\omega)$ given by Eq. (4)) and Eq. (14), have been computed, as a function of frequency, in the range from $0.01 \mathrm{~Hz}$ to $1 \mathrm{kHz}$. In Figure 4, we present values for $\left|\rho^{*}(\omega)\right|$, for a frequency sounding with $a=100 \mathrm{~m}, n=6$, and the following specifications for $\rho^{\star}(\omega) \rho_{0}=10 \Omega$.m; $m_{w}=0.25$; and $\tau_{w}=0.5 \mathrm{~s}$. The open diamond symbols are the synthetic results in which both polarization and EM coupling are present (Eq. (7)). The black circles represent the results in which EM coupling effects are absent, with the amplitude and phase of $\rho^{\star}$ being computed using Eqs. (14) and (15).

Certain features of these results are noteworthy: (i) The curves for $\left|\rho^{\star}(\omega)\right|$ and $\varphi$ from Eqs. (7) and (8) converge to those of pure IP (Eqs. (14) and (15)) at low frequencies; (ii) The deviations between the curves become appreciable when the frequency exceeds several tens of $\mathrm{Hz}$. Therefore, an effective procedure for data reduction, should use only the portion of the IP data below a certain limiting frequency, and a specified function to fit experimental data. Although it is difficult to define a boundary between pure IP and EM coupling, it is possible, using a trial-and-error procedure, to find the maximum frequency to be used in the fitting process, as shown in the examples described below. Using this procedure, it is possible to obtain the proper values for the apparent parameters $\rho_{0, \mathrm{a}}, m_{\mathrm{w}, \mathrm{a}}$ and $\tau_{\mathrm{w}, \mathrm{a}}$ to use in the inversion and interpretation of SIP data.

\section{Time Domain}

A TD induced polarization survey is analyzed considering the transient curve $\Delta \varphi(t)$ obtained after interrupting the injection of an active step-function current into the ground. This curve describes the secondary electric field created by the IP phenomenon. The main features of such curves are shown in Figure 5. At the instant the transmission current is turned on, the potential difference is $\Delta \varphi_{a c}$. This value is difficult to measure in practice due to the transient effects of the EM coupling. $\Delta \varphi_{D C}$ is the potential difference measured at the end of the current semi-cycle $T / 2$, which tends toward an approximately constant value with increasing $T$. The potential difference at the instant of interruption of the current is $\Delta \varphi_{s}$. This parameter is also not 


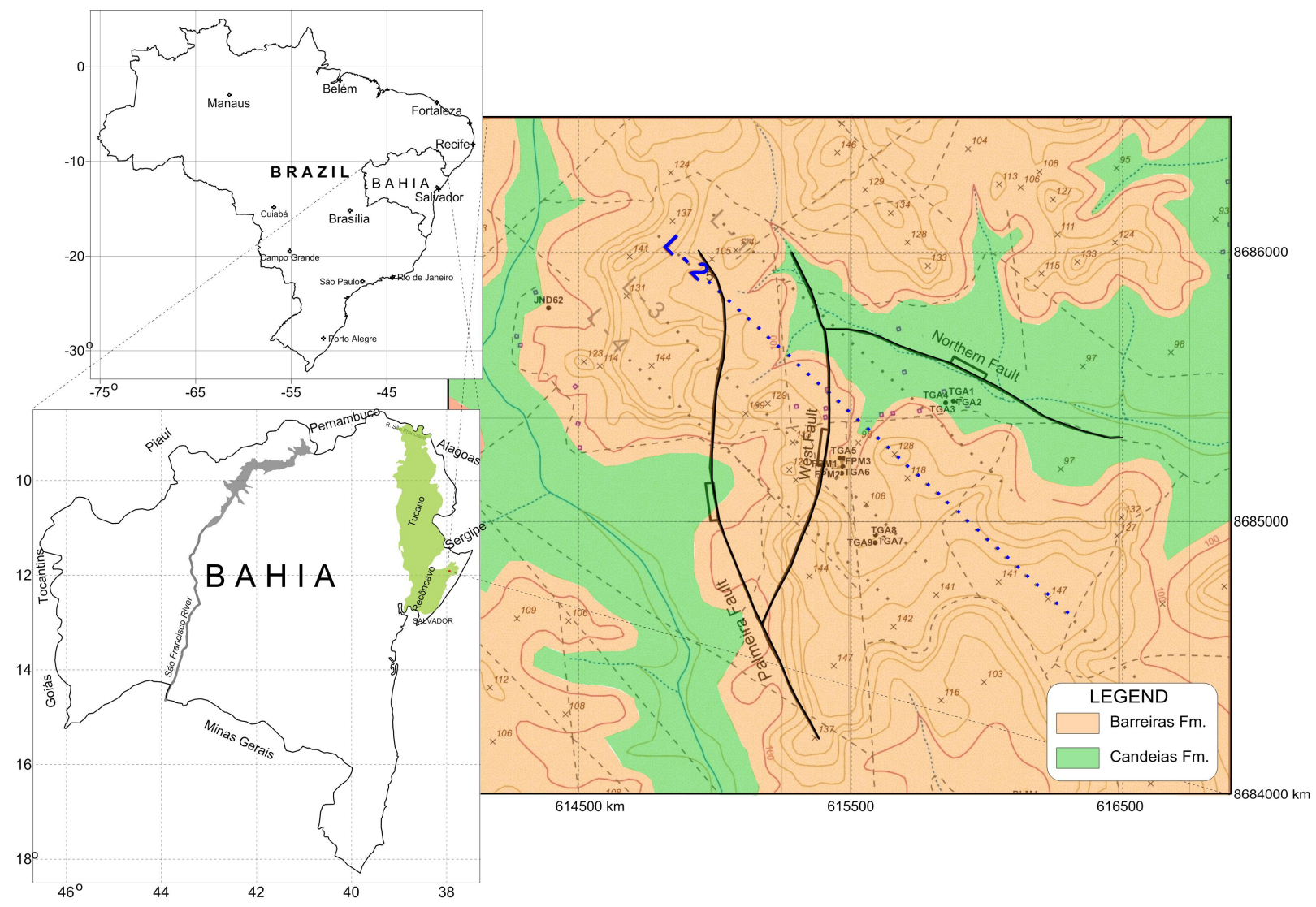

Figure 3 - Location map of the study area and of the transverse profile crossing the studied reservoirs in the Recôncavo sedimentary basin, Bahia, Brazil.

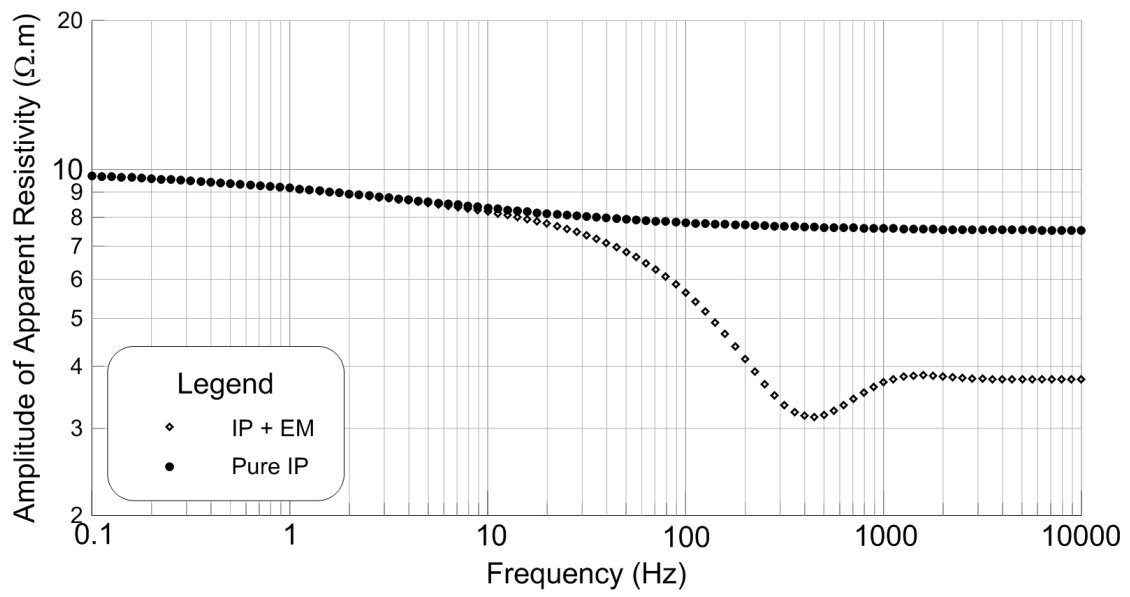

Figure 4 - Theoretical dipole-dipole apparent resistivity for a homogeneous half-space using Dias' model with $\rho_{0}=10 \Omega . \mathrm{m}, m_{W}=0.5, \tau_{W}=0.5 \mathrm{~s}$; for $a=100 \mathrm{~m}$ and $n=6$. EM coupling and pure IP effects. 


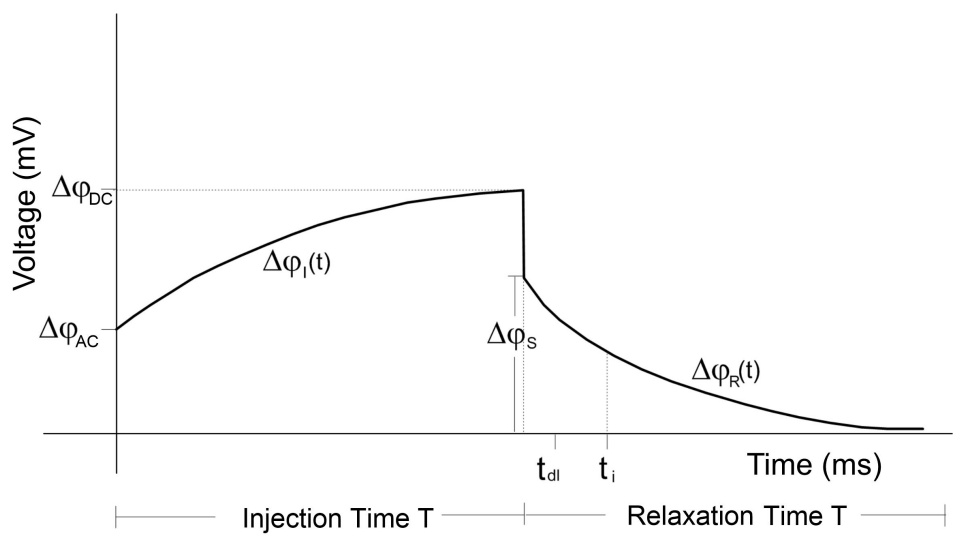

Figure $\mathbf{5}$ - Sketch of the electrical potencial changes during a charging and discharging period of a time domain IP field survey.

measurable, due to instrumental effects caused by the transient shutdown.

According to the Seigel's formulation (Seigel, 1959), the intrinsic chargeability of a homogenous, polarizable half-space observed with a DC-electrical system is given by

$$
m_{o}=\frac{\Delta \varphi_{D C}-\Delta \varphi_{a c}}{\Delta \varphi_{D C}} .
$$

In case of a heterogeneous half-space, Eq. (16) is used to compute an apparent chargeability function.

In practice, a partial $\Delta \varphi_{t_{d l}}\left(t_{i}\right)$ is easy to measure at short $\Delta t$ intervals for the $i$-window after the current shutdown (after a delay time, $\left.t_{d l}\right)$. An apparent partial chargeability is calculated using the equation

$$
m_{a_{i}}\left(t_{i}\right)=\frac{\Delta \varphi_{i}}{\Delta \varphi_{D C}} .
$$

A global apparent chargeability is then calculated using the expression

$$
m_{a, g}=\frac{\sum_{i=1}^{n} m_{a_{i} \Delta \Delta_{i}}}{\sum_{i=1}^{n} \Delta t_{i}},
$$

where $n$ is the number of windows in which $m_{a i}$ values were measured. The value of $m_{a, g}$ may be expressed in $\%$ or $\mathrm{mV} / \mathrm{N}$. The partial and the global chargeability provide information on the subsurface electrical IP sources activated by the alternating current flux (Vacquier et al., 1957; Bertin \& Loeb, 1976; Binley \& Kemna, 2005).

According to Wait (1984), the time domain equivalent or the Laplace transform of Eq. (11) may be written as

$$
m(t)=m_{o} e^{t / \tau_{w}} \operatorname{erfc}\left[\left(\frac{t}{\tau_{w}}\right)\right] .
$$

Equation (19) may be simplified, for large and small values of $t$, by exploring the asymptotic values of $e^{x^{2}} \operatorname{erfc}(x)$ for large and small $x$. Thus, for $t \ll \tau_{w}$

$$
m(t)=m_{o}\left[1-\left(\frac{2 t}{\pi \tau_{w}}\right)^{1 / 2}\right] .
$$

and for $t \gg \tau_{w}$

$$
m(t)=m_{o} \frac{1}{\pi^{1 / 2}}\left[\left(\frac{\tau_{w}}{t}\right)^{1 / 2}-\frac{1}{2}\left(\frac{\tau_{w}}{t}\right)^{\frac{3}{2}}+\cdots\right],
$$

which has a slower decay than one simple exponential function.

For TD data reduction, several authors have derived analytical expressions to describe the phenomenon of transient IP over uniform or 1-D conductive and polarizable terrains (Millett, 1967; Mocitaiba et al., 2017). Typically, the theoretical results are represented by complicated mathematical functions, in the form of integrals of Bessel functions, which require a lot of computation for practical use. By analogy with the frequency domain IP, it is proposed to represent the apparent chargeability decay given by Eq. (21) as a sum of exponential functions in the form

$$
m_{a}(t)=\sum_{i=1}^{n} c_{i} e^{-t / \tau_{i}},
$$

where $c_{i}$ are the time-intersects and $\tau_{i}$ the time-constant or relaxation-constant for a component decay process. This type of representation has been used before, as described in the literature (Bertin \& Loeb, 1976).

Analysis of experimental curves for an apparent partial chargeability function shows, in practice, that only two or three exponentials are sufficient to represent a typical IP discharge curve. 

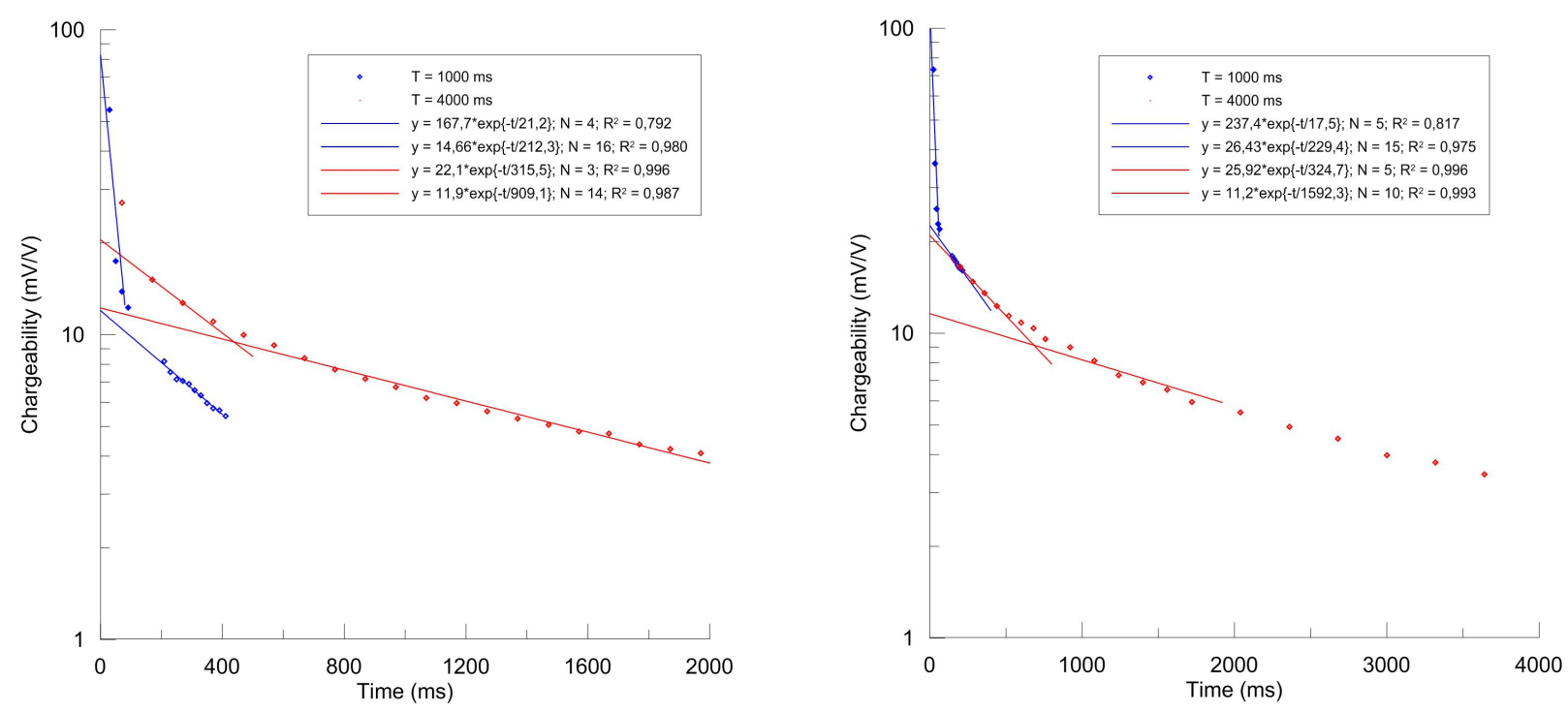

Figure 6 - Experimental IP discharging curves for the first and last current dipole best fitted to exponential functions for separating EM coupling and true IP effects.

The curves depicted in Figure 6 were constructed using the data for the first and last current dipoles of the $50 \mathrm{~m}$ IP-TD survey line with $n=1$, as described. This special data was acquired with two different charge-discharge regimes ( $T=$ $1,000 \mathrm{~ms}$ and $\mathrm{T}=4,000 \mathrm{~ms})$, a time delay $t_{d l}$ of $20 \mathrm{~ms}$, and 20 time-windows of different sizes, producing a clearly defined interval of superposition. The discharge curves of Figure 5 appear to consist of at least two distinct parts: i) a rapid initial discharge with a small time-constant $\tau_{1}$, which is predominantly caused by EM coupling effects and typically lasts for tens to a few hundred milliseconds; and ii) a slow discharge with a large time-constant $\tau_{2}$, which is purely due to the effects of the subsurface IP. These features describe a total chargeability that is dependent on the used charging-discharging period. Based on the observed behavior, the following reduction process is proposed.

Because the two main exponentials have quite distinct time-constants, the first will decay rapidly, only the second will remain after an arbitrary acquisition time $t_{\text {min. }}$. Thus, by fitting the experimental data to an exponential function above an estimated $t_{\min }$, the results will allow us to compute $\Delta \varphi_{s}$ and $\tau_{a, w}$ for the pure IP, which in turn leads to a more appropriate calculation for $m_{a, g}$ (Fig. 6).

\section{GEOLOGICAL SETTING}

The Recôncavo-Tucano-Jatobá sedimentary basin developed during the Juro-Cretaceous lithospheric rifting that accompanied the breakup of Pangaea (Milani \& Davison, 1988). The basin formed as an asymmetric graben oriented from NE to SW, with the deepest faults along its eastern border, with the strata dipping to east. The basin substratum is composed of intensely sheared Precambrian gneissic rocks, with extensive mylonite zones also oriented along NE-SW.

The sedimentary basin fill was deposited in three main tectonic phases: pre-rift, syn-rift and post-rift. During the pre-rift stage, inter-layered shale and sandstone bodies were deposited inside one elongated depression developed before the rifting. During the rift phase, tectonic activity and subsidence were intense, leading to the formation of inter-fingered lacustrine deposits and conglomerates, along the edge of the faulted border. In this stage, the organic matter preserved in shale bodies deposited within depositional centers within the basin, matured generating hydrocarbons that migrated upward and laterally. The post-rift phase was characterized by marine and fluvial deposits, unconformably overlaying the described stratigraphic sequence (Figueiredo et al., 1994; Silva et al., 2007).

The pre-rift sequence includes three broad overlapping cycles of fluvio-eolian sand deposits representing the main hydrocarbon and aquifer reservoirs. Regional lacustrine deposits separate these cycles and are dominantly represented by the pelitic sediments.

The rift section includes three sequences: i) The lower section includes shales, limestones and turbidity sandstones, which represent the early stages of high subsidence rates; ii) A quiescent tectonic phase was accompanied by an increase in 
sediment supply and contributed to the infilling of the depressed areas within the basin. In certain depositional centers, this deposition involved a large volume of gravity-flow deposits; and iii) the upper sequence records the expansion of deltaic lake systems, with a gradual southward retraction. During this time, thick tabular shaly-sandstone bodies were deposited and were inter-bedded with shale and fine-grained sandstones.

The local geology of the study area is relatively simple (Figs. 2 and 3). The hydrocarbon reservoir body consists of a succession of fluvio-eolian, coarse-grained shaly-sandstones of the Água Grande Formation, and the strata dips uniformly $10^{\circ}$ to southeast. These deposits overlie the extensive shale sequence of the Itaparica Formation and are covered by the Candeias Formation, another predominantly shale sequence. Candeias Formation is the main hydrocarbon source-rock sequence in the basin, being composed mainly of shale and lenticular sandstone and limestone bodies. It is subdivided into two members: The basal Tauá Member consisting of dark-gray shales, and the Gomo Member characterized by dark-gray to greenish-gray calcareous and dolomitic shales. The reservoir is laterally bounded by conjugate normal faults, oriented NE-SW and NW-SE. In general, these faults are impervious, either due to structural damage along the faults or simply due to the juxtaposition of sandstones against shale layers. Above an erosional disconformity, the Tertiary deposits of Barreiras Formation, mainly composed of inter-bedded sandstones and shale lenses, represent the main aquifer system in the area. Thin fluvial Quaternary deposits cover all the described sedimentary sequences.

\section{IP FIELD EXPERIMENTS}

Electrical surveys using IP-resistivity methods were conducted on the area of a producing oil field in the Recôncavo basin, Bahia state, Brazil. In plan view, the studied reservoir has a wedge-shaped geometry, defined by the intersection of two normal fault zones (Fig. 3). The work was performed along a 1,900 $\mathrm{m}$ survey line oriented across the geological structure of the area. Two overlapping IP-resistivity sections, one FD and the other TD, were performed using dipole-dipole electrode arrays. The large FD transverse was obtained using a dipole length $a=100 \mathrm{~m}$ and separations $n a$, with $n$ varying from 1 to 12 . The smaller (1200 m) TD section, initiated at the same point (E-5) was made with dipole lengths of 50 and $100 \mathrm{~m}$, and $n$ varying from 1 to 6 .

Two geophysical instruments were used for these acquisitions: i) a high-power System 2000.net from Phoenix Geophysics, consisting of a TXU-30/RXU-TM transmitter of $20 \mathrm{~kW}$ and two V8 multifunction receivers, operating in the
SIP mode; and ii) a low-power VIP 3000 transmitter of $3 \mathrm{~kW}$, and an ELREC Pro multichannel receiver, from Iris Instruments, operating in time domain.

The transmitter system TXU-30 comprises: i) a three-phase motor-generator of $30 \mathrm{kVA}$, used to energise the system; ii) a multifunction current-source connected to a control unit for setup and monitors waveforms, according to a programmed data stored in a flash card memory; iii) a sensor and register unit for recording the actual amplitude and phase of the current. To control and measure the phase each part has a built-in GPS (Global Positionig System) satellite-syncronized timing control.

The V8 is a multi-functional receiver and has three magnetic channels and three electrical channels used to measure electrical potential differences in the ground. It is permanently syncronized to GPS time and is optimized to operate with a transmitter similarly syncronized to GPS time. In SIP mode, only the electrical channel are used, connected to the porous pot electrodes.

Aluminum plates of $0.80 \times 0.50 \mathrm{~cm}$ dimensions, buried 80 $\mathrm{cm}$ deep in the soil and fully wetted with salty water mud, were used as current source electrodes. Each current pair was then connected to the TXU-30 transmitter system. Eight porous pots, containing a lead electrode wire in contact with a $\mathrm{PbCl}_{2}$ solution, were used as potential electrodes, also buried in the topsoil. Two V-8 multi-functional receivers were used for the simultaneous acquisition of six dipole data. Finished the measurements, the receivers, cables and porous pots were moved to complete the first dipole-dipole sounding. The transmitter set was then displaced to the next position to complete 17 electrical soundings along the line.

The maximum output current from the VIP 3000 transmitter, energized by a $4.5 \mathrm{kVA}$ motor generator, is $5 \mathrm{~A}$. The receiver unit ELREC Pro allows connecting 10 reception dipoles, performing 20 partial chargeability measurements with high accuracy. Copper stakes $1 \mathrm{~m}$ long and the same set of porous pots were used as source and measuring devices. The source electrodes were driven into the topsoil layer and flushed with salty waters to reduce the contact resistances and to obtain reasonable signal-to-noise ratios, even for the large values used for $n$.

The dipole-dipole array was selected due to its good spatial resolution and capability to resolve narrow vertical structures having contrasting electrical properties (Loke \& Barker, 1996; Dahlin \& Zhou, 2004). However, instead of using the conventional construction of a dipole-dipole pseudo-section, we adopt the "effective" or median depth of investigation for the array, as proposed by Edwards (1977). This concept allows not only to 

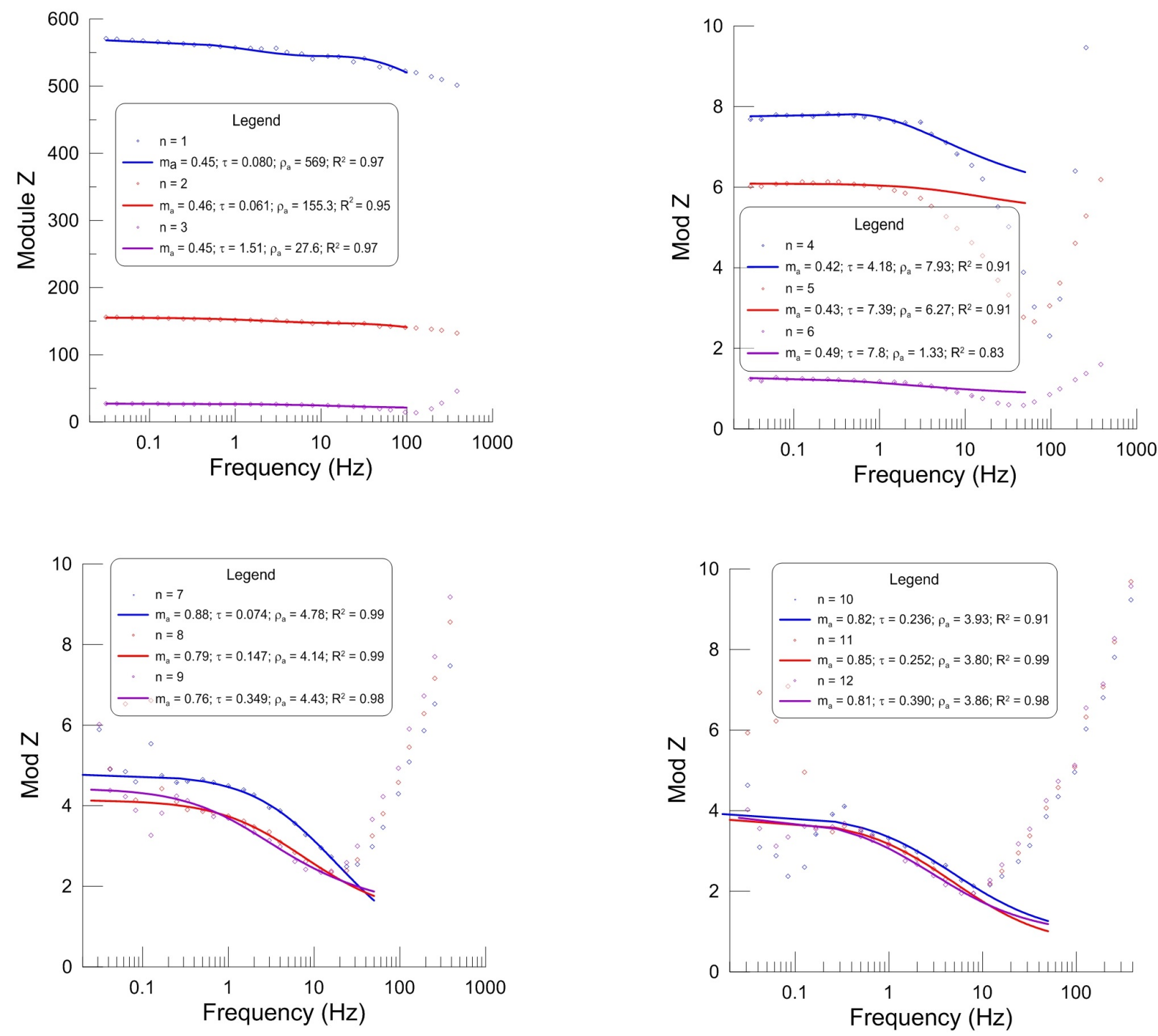

Figure 7 - Plots of the amplitude measurements, as a function of frequency, obtained at current dipole \#4 and their fitting to Dias' resistivity function (Eq. 14) for EM coupling reduction.

place the imaged anomalous features in a more consistent vertical position but, also, to combine data sets obtained with different dipole lengths (TD $a=50 \mathrm{~m}$ and $a=100 \mathrm{~m}$ ) into a coherent, unique pseudo-section.

\section{The FD Experiment}

The acquired data sets for line L-2 were processed to reduce the EM coupling from the IP effects using the procedure described in subsection Frequency Domain. Figure 7 depicts several examples of processed results from the FD field survey for the fourth current dipole and $n=1, \ldots 12$. In the least squares best fit to these data, the GRAPHER package version 9 from Golden Software has been used, with the option to define the fitting function in accordance with Eq. (14). The curve legend shows the best fitted values for the parameters of Eq. (14) and the corresponding coefficient of determination $\mathrm{R}^{2}$. In general, the results are quite satisfactory, although some noise may be present in the lower frequencies of the acquisition interval.

Figure 8 contains the results obtained with the SIP method along line L-2 in the form of pseudo-sections of apparent DC-resistivity, apparent chargeability and apparent relaxation time. The qualitative interpretation of these images allows 

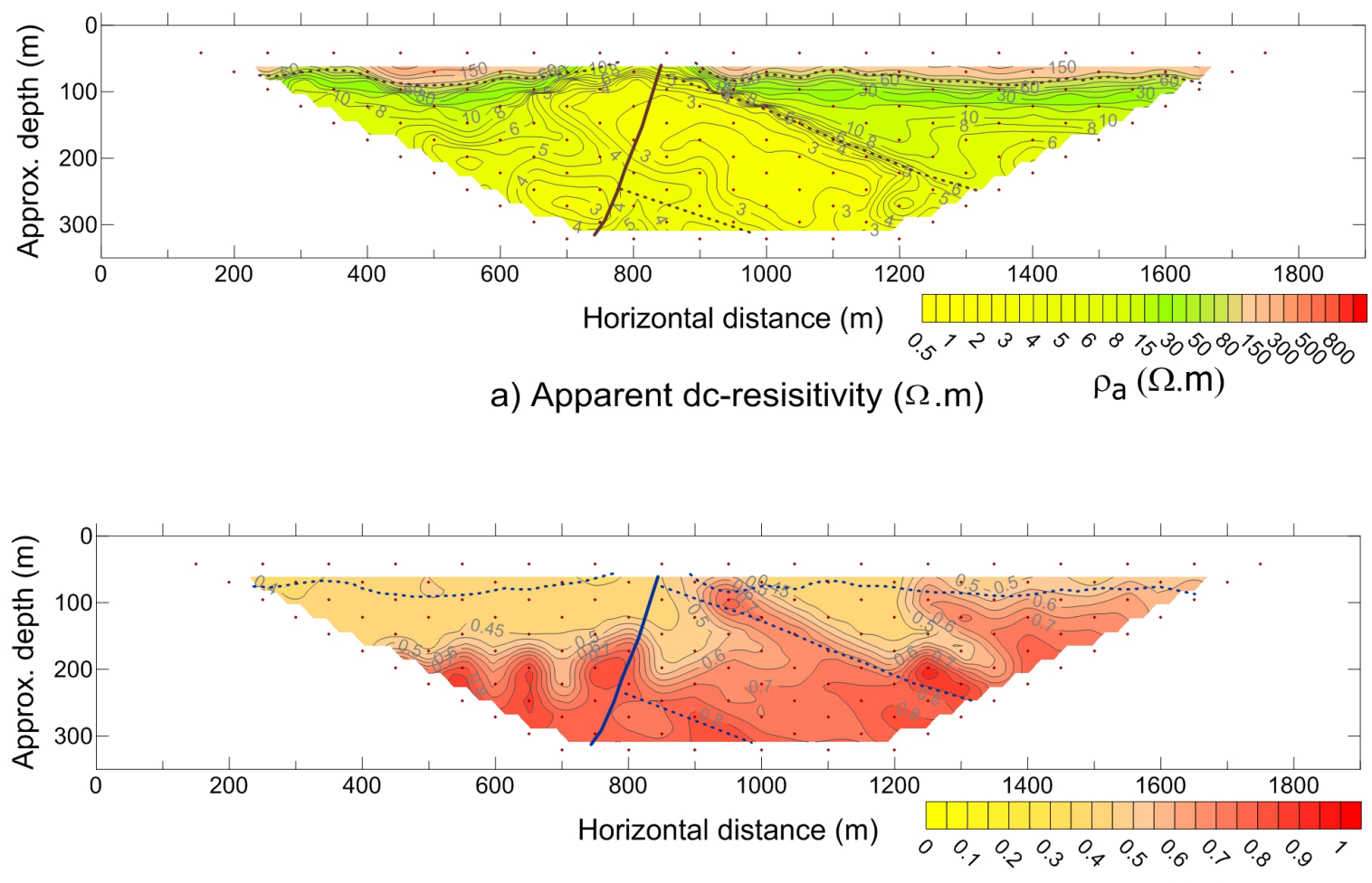

b) Apparent chargeability $\quad m_{a}(m V / N)$

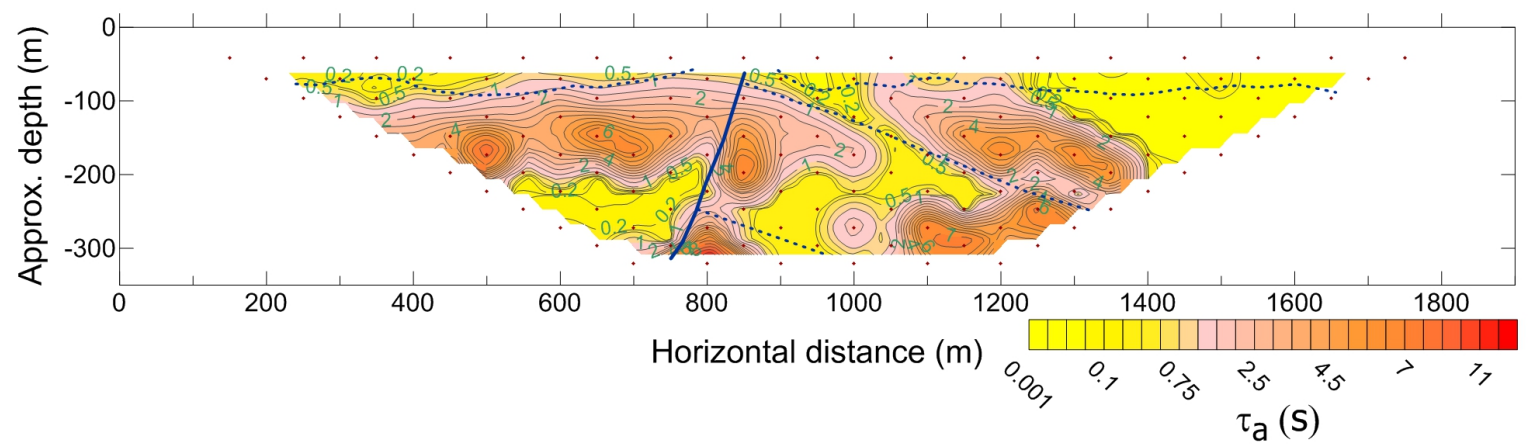

c) Apparent relaxation time (s)

Figure 8 - Geo-electrical cross-sections of apparent resistivity and IP frequency domain parameters $\left(m_{W}, \tau_{W}\right)$ derived from the amplitude data of line $\mathrm{L}-2$.

recognizing the presence of an upper layer of high resistivity and low chargeability, representing the Barreiras sandstone aquifer. Underlying this sand body is a thick shale sequence, with two distinct ranges of apparent resistivity values: an upper one with $\rho_{a}$ values ranging from 6 to $15 \Omega$.m, and a lower one with values bellow $5 \Omega . \mathrm{m}$. The apparent electrical images also show the West Fault zone bounding the upper side of the reservoir block, in the right portion of these sections.
The geo-electrical sections of $\rho_{a}$ and $m_{a}$ were inverted using the RES2DINV package from Geotomo Software, to generate the actual resistivity and IP distribution models (Geotomo, 2010; Loke, 2015). The 2-D models normally used by this program, consist of a number of rectangular blocks, whose sizes and distribution are automatically generated from the data point distribution in a given pseudo-section. A forward finite-difference or finite-element modeling scheme 

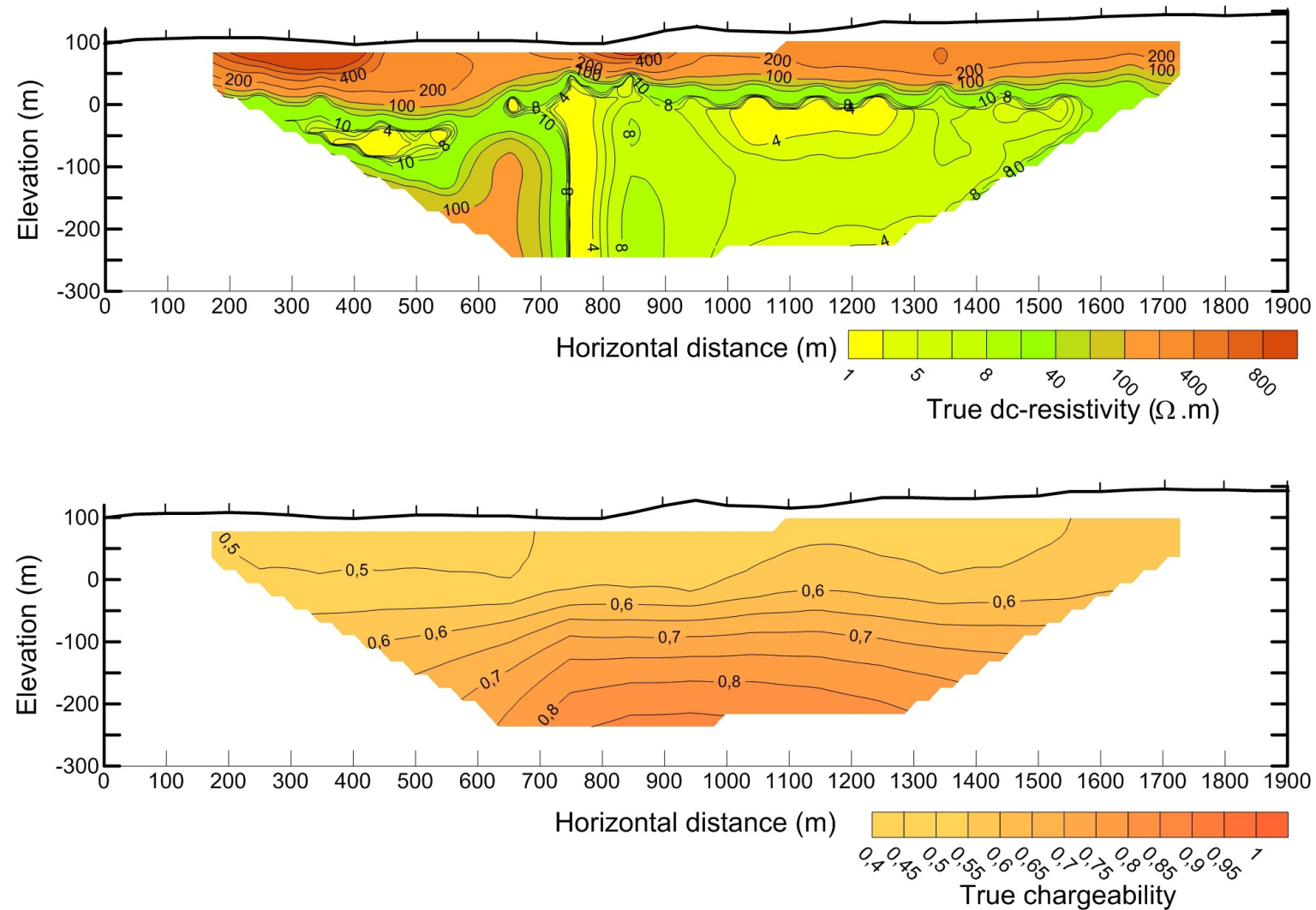

Figure 9-2-D inverted electrical images for the true resistivity and chargeability parameters using the data of Figure 8 . Absolute error $9.3 \%$ after 7 iterations.

is used to compute the values of the apparent electrical $\rho_{a}$ and $m_{a}$ functions along the profile. A non-linear least-square optimization technique was used to best fit the observed data set. Topographic data were incorporated into the inversion process of the two cross-sections.

The inverted resistivity image is quite rich in geological details (Fig. 9). The Barreiras aquifer is shown as a high true resistivity layer (> $200 \Omega . \mathrm{m}$ ), and a thickness varying between a few meters and more than $60 \mathrm{~m}$. The West Fault damage zone is depicted as a central narrow conductive chimney $(<2 \Omega$.m) bordered by more resistive belts, that probably reflects the mechanical damages, the diagenetic alterations caused by old migration paths of fluids and even the presence of vertically distributed hydrocarbon pockets. Some low conductivity lenticular shale bodies may be delineated between stations $11(300 \mathrm{~m})$ and $16(600 \mathrm{~m})$ and between stations 25 $(1000 \mathrm{~m})$ and $35(1500 \mathrm{~m})$. Note a slight increase in resistivity at the right of the fault zone, interpreted as the top of the oil reservoir.

The inverted chargeability model is less diagnostic regarding the investigated structure. The image allows only to recognize the fault trace by the lateral inflexions in the contour lines, and the top of the reservoir, associated to a sharp increase in $m_{w}$, up to a value $>0.8$. The strong resistivity and moderate IP anomaly in the left side of the fault surface, in an area that is not being explored by any well, may also contain hydrocarbons stored in shale fractures and in sandstones on the lower side of the faulted block.

\section{The TD Experiment}

The superposed time domain IP-resistivity sections were performed along line $\mathrm{L}-2$, in its first $1200 \mathrm{~m}$ extension. Figure 10 contains the exponential fits to the TD partial chargeability data obtained at the current dipole \#4 ( $a=50 \mathrm{~m}$ and $n$ ranging from 1 to 6). Although some dispersion is observed with increasing $n$, the data are reasonably described by the adjusted procedure described in subsection Time Domain. The adjusted parameter and relative errors are given inside the figure legend.

The apparent resistivity, chargeability and time-constant pseudo-sections in Figure 11 were obtained by superposing the dipole-dipole arrays with $a=50 \mathrm{~m}$ and $a=100 \mathrm{~m}$ 

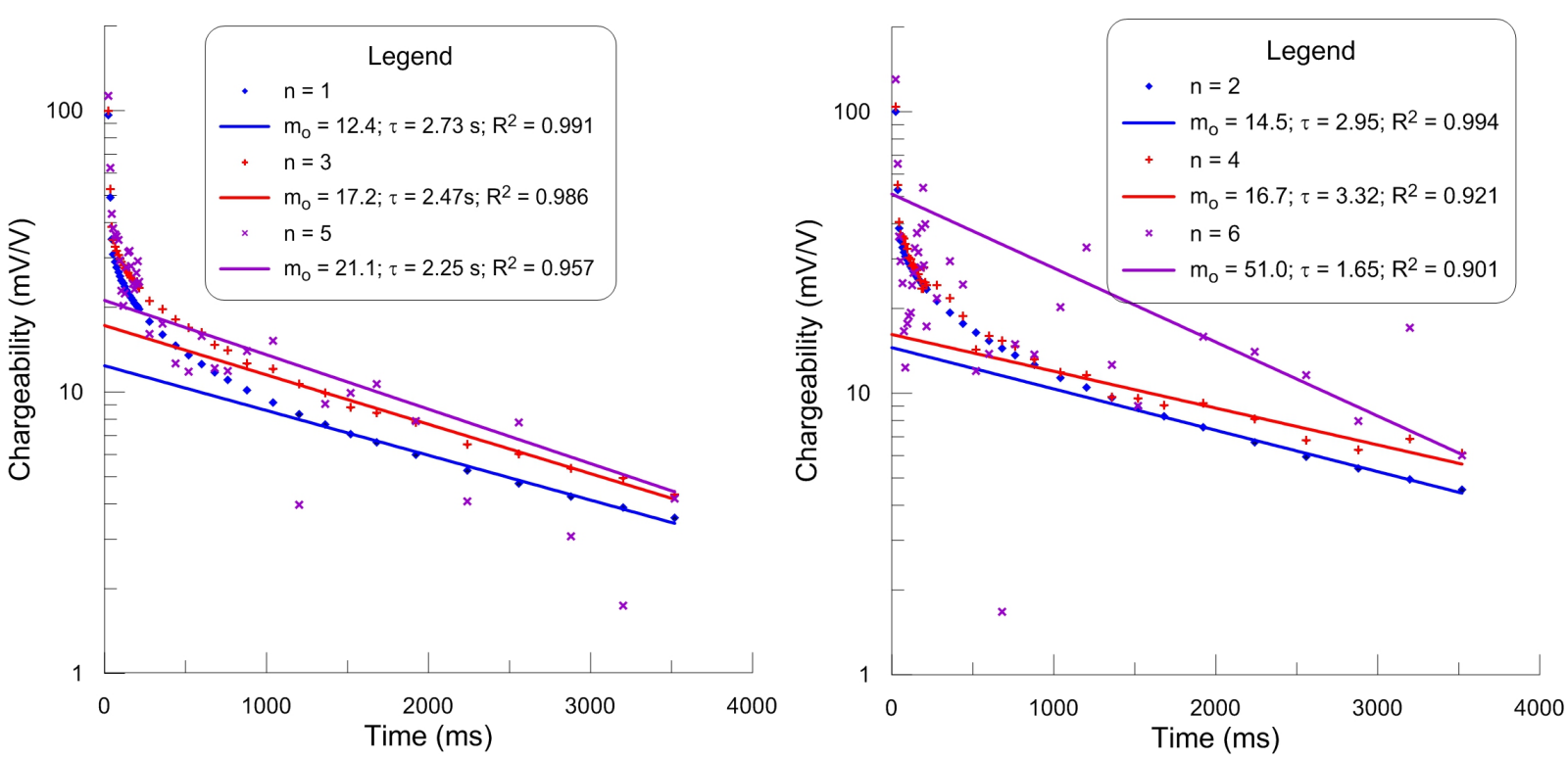

Figure 10 - Experimental IP discharging curves fitted to large time exponential functions for reduction of EM coupling effects in TD measurements.

and $n$ ranging from 1 to 6 . Due to this combination, the resultant pseudo-sections are more representive of the aquifer and its substratum characteristics, to a maximum depth of $180 \mathrm{~m}$. The lithological contacts and the fault trace delineated over the apparent parameter sections of Figure 10 are only approximations. The fault trace was drawn using both the apparent resistivity and the chargeability contrasts. Note the distinctive values of the apparent relaxation time, above $2.5 \mathrm{~s}$ within the Barreiras sandstone, and bellow $1.8 \mathrm{~s}$ within most of the shale cover. This may be a result from different mean size of the sand clay-coated particles distributed in the aquifer, and a smaller grain-size in the disseminated metallic minerals within the shale.

The apparent images show high $\rho_{a}$ and low $m_{a}$ values $\left(\rho_{a}\right.$ values between 500 and 1,000 $\Omega . m$ and $m_{a}$ values of $<0.15$ ) up to depths of approximately $60 \mathrm{~m}$, reflecting the sandstone cover of the Barreiras Formation. Underlying this resistive layer, a thick conductive layer $\left(2 \leq \rho_{a} \leq 10 \Omega . \mathrm{m}\right)$ is related to the shale sequence of the Candeias Formation. Note a slight lateral resistivity contrast near the West Fault surface and an increase in chargeability with depth below $100 \mathrm{~m}$. In the $m_{a}$ image, the Barreiras sandstones show low chargeability bellow $0.1 \mathrm{mV} / \mathrm{N}$, whereas some zones within the Candeias seal may reach values above $1.5 \mathrm{mV} / \mathrm{N}$.

The characteristics of the described IP anomaly can be better appreciated by considering the curves in Figure 10, which show the patterns of variation in the partial apparent chargeability values with time and depth of penetration of the electrical currents. There is a notable increase in the total chargeability with increasing $n$, as well as a greater variation in the relaxation times of polarization.

The pseudo-sections were inverted with RES2DINV package using again the robust constraint and allowing the number of cells to exceed the number of data points. Due to the more detailed data acquisition, the inverted images give a better definition of the aquifer geometry and of its substratum.

In Figure 12, the inverted 2-D quantitative results for the two upper pseudo-sections are shown in terms of the true resistivity and chargeability distribution. From both images, it is possible to observe that the Barreiras aquifer (high resistivity, low chargeability) is a discontinuous sand-pack, interrupted or very thin, after station 21 (850 $\mathrm{m}$ from origin). The damage zone of the West Fault is shown as a vertically segmented structure, more conductive and weak-polarizable than the hosting shales. Within the Candeias shale sequence an increase in the true $m_{w}$ with depth is also observed.

Notably, the thin vertical conductive tabular body, identified in Figure 6, is also present bellow station 21 ( $800 \mathrm{~m}$ from the origin) with the fault zone being revealed as an irregular surface dipping to west. Large chargeability values are concentrated on the footwall block, below the fault surface. The IP anomalies, 

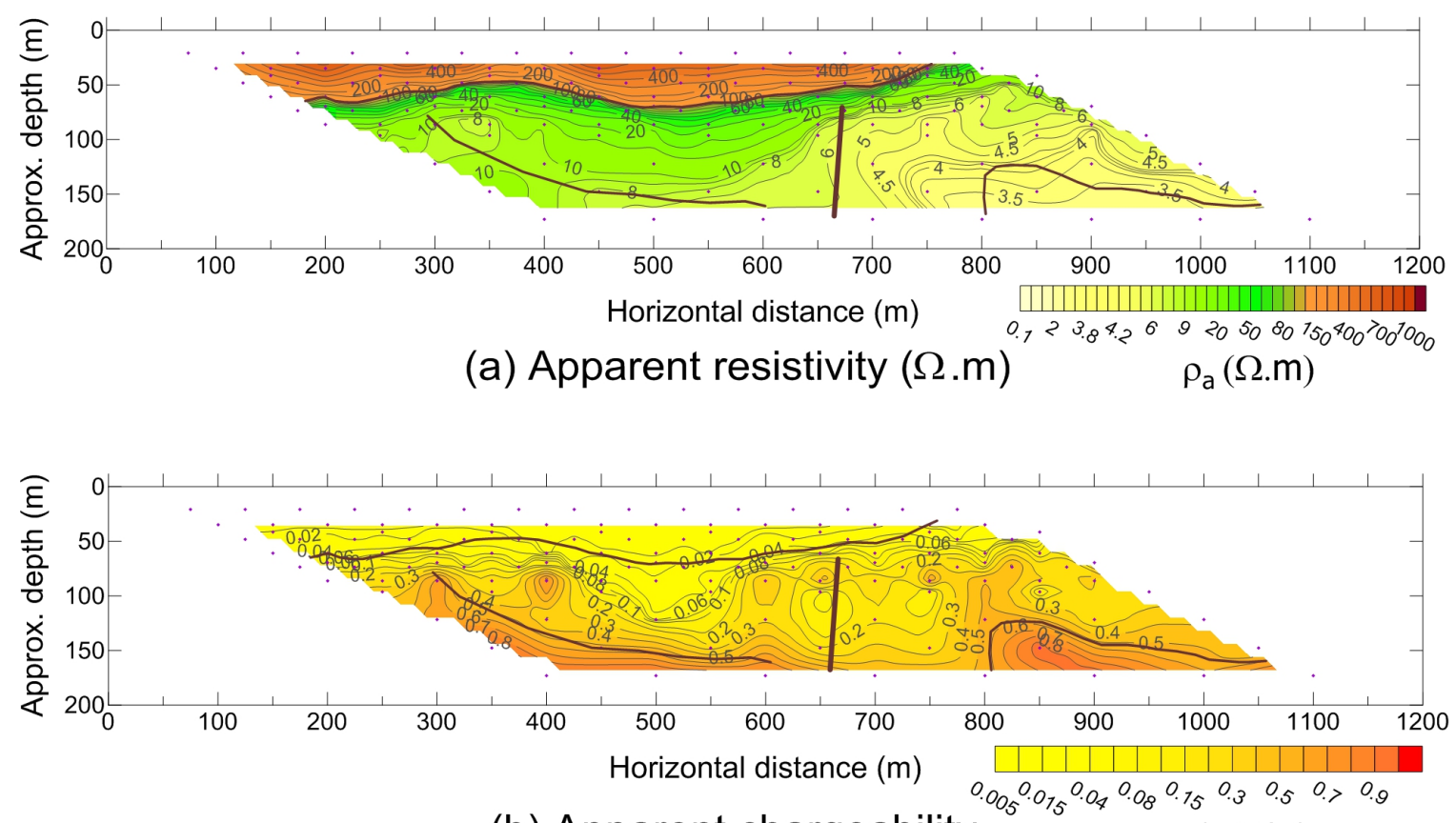

(b) Apparent chargeability

$\mathrm{m}_{\mathrm{a}}(\mathrm{mV} / \mathrm{V})$

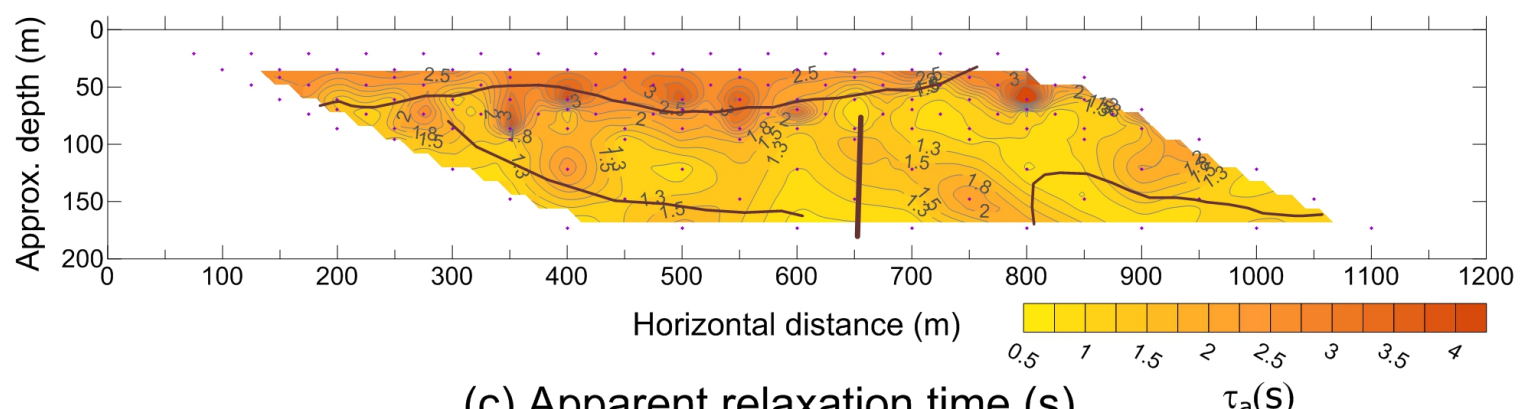

(c) Apparent relaxation time (s)

$\tau_{\mathrm{a}}(\mathrm{s})$

Figure 11 - Geo-electrical cross-sections of apparent resistivity and IP time domain parameters $\left(m_{0}, \tau_{0}\right)$ derived from discharging data of line L-2.

larger than those of the Barreiras and upper portion of Candeias formations, are attributed to metallic minerals precipitated along conjugate fractures developed in the shale sequence below the fault trace. A chargeability anomaly, also present in the hanging wall block, may be taken as suggesting the existence of hydrocarbons in the underlying sandstones migrated through the Palmeiras Fault (see Fig. 3).

\section{CONCLUSIONS}

The comparison of data obtained using two IP-resistivity surveys in the test oil field reveals small differences in resolution and distortions in the inverted geological models. These differences can be attributed to differences in power, variable water saturation within the aquifer vadose zone, and different noise effects. The distortions were large for the IP measurements, which are more sensible to local heterogeneities such as well casings, electrical transmission lines and underground pipelines. Although the investigated structure is truly 3-D, its strike-length is at least 3 to 5 times the average depth to the reservoir, what makes the 2-D inverted results to be considered a satisfactory geological approximation.

The derived information is consistent with the following results: (i) the delineation of an upper resistive low chargeability layer, representing the sandstone aquifer of Barreiras Formation; 

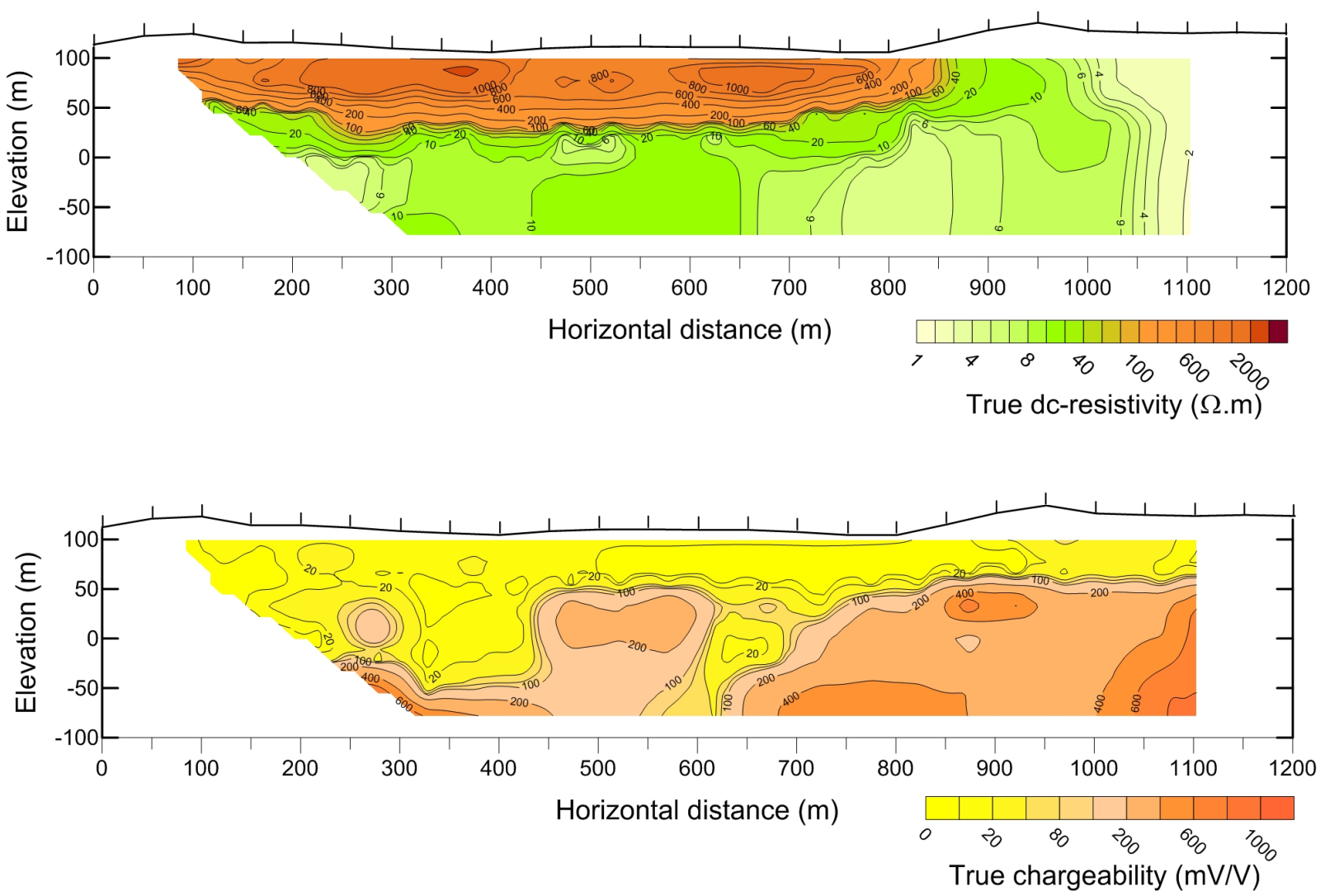

Figure 12 -2-D inverted electrical images for the true resistivity and chargeability parameters using the data of Figure 11 . Absolute error $7.3 \%$ after 6 iterations.

(ii) the identification of distinct electrical horizons within the Candeias shale sequence; (iii) the marked presence of the western bounding fault zone and its subvertical damage structures, depicted as a conductive chimney. The width of this zone is larger than $100 \mathrm{~m}$ at the fault top, decaying to less than $50 \mathrm{~m}$ at the maximum investigates depth; and (iv) the weak delineation of the upper portion of the hydrocarbon reservoir, defined by a slight increase in resistivity and a localized increase in chargeability with depth above the reservoir extent.

Therefore, these results demonstrate the feasibility of using the IP-resistivity method to explore for aquifer and hydrocarbon reservoirs in continental areas, and at shallow depths. The main requirement is that the reservoir dimensions and its depth extent are well related to the sample spacing, such that it may be detected by precise changes in electrical properties.

An important question regarding the application of EM methods in geophysical exploration is that the IP and EM propagation effects cannot be separated during the field acquisition process. Fortunately, although they are transient phenomena mutually interfering, their range of influence can be distinguished through an acquisition procedure involving a large frequency spectrum or a long time interval. The separation processes proposed here can be used in practice to compute the main electrical parameters for the IP-resistivity interpretation.

\section{ACKNOWLEDGMENTS}

The authors are grateful to PETROBRAS, both for providing financial support to this research project and for allowing the publication of these results. The authors also acknowledge the CNPq - Conselho Nacional de Desenvolvimento Científico e Tecnológico (Brazilian National Council for Scientific and Technological Development) for support through the INCT Instituto Nacional de Ciência e Tecnologia (National Institute of Science and Technology) in Petroleum Geophysics (GP) and for the support of a research fellowship to 0 . Lima. Thanks are also due to CPGG/UFBA for the infrastructure support for this research.

\section{REFERENCES}

ANGORAN Y \& MADDEN TR. 1977. Induced polarization: A preliminary study of its chemical basis. Geophysics, 42: 788-803. 
BARKER ND, MORTEN JP \& SHANTSEV DV. 2012. Optimizing EM data acquisition for continental shelf exploration. The Leading Edge, 31 : 1276-1284.

BARRETO AN \& DIAS CA. 2014. Fluid salinity, clay content, and permeability of rocks determined through complex resistivity partition fraction decomposition. Geophysics, 79: 1-15.

BERTIN J \& LOEB J. 1976. Experimental and theoretical aspects of induced polarization. (2 Vol.). Geoexploration Monographs, Series 1, Geopublication Associates, Berlin.

BINLEY A \& KEMNA A. 2005. DC resistivity and induced polarization methods. In: RUBIN Y \& HUBBARD SS (Eds.). Hydrogeophysics. Springer Verlag. p. 129-156.

BJORLYKKE K. 1988. Diagenesis I, Development in Sedimentology. In: CHILINGARIAN GV \& WOLF KH (Eds.). American Association of Petroleum Geologists. Oklahoma, USA. Memoir 37: 239-276.

BLEIL DF. 1953. Induced polarization, a method of geophysical prospecting. Geophysics, 18: 636-661.

BOADU FK \& OWUSU-NIMO F. 2010. Influence of petrophysical and geotechnical engineering properties on the electrical response of unconsolidated earth materials. Geophysics, 75: 621-629.

BOADU FK \& SEABROOK B. 2006. Effect of clay and salinity on the spectral electrical response of soils. Journal of Environmental and Engineering Geophysics, 11: 161-170.

BÖRNER FD, GRUNE M \& SCHÖN JH. 1993. Contamination indications derived from electrical properties in the low frequency range. Geophysical Prospecting, 41: 83-98.

BROTHERS LA, ENGEL MH \& ELMORE RD. 1996. The late diagenetic conversion of pyrite to magnetite by organically complexed ferric iron. Chemical Geology, 130: 1-14.

COGGON JH. 1984. New three point formulas for inductive coupling removal in induced polarization. Geophysics, 49: 307-309.

COLLETT LS. 1990. History of the induced-polarization method. In: FINK JB, MCALISTER EO, STERNBERG BK, WIEDUWILT WG \& WARD SH (Eds.). Induced Polarization, Applications and Case Histories. Society of Exploration Geophysicist. USA. Investigations in Geophysics, 4: 5-22.

DAHLIN T \& ZHOU B. 2004. A numerical comparison of 2D resistivity imaging with ten electrode arrays. Geophysical Prospecting, 52: 379-398.

DAVYDYCHEVA SN, RYKHLINSKI D \& LEGEIDO P. 2006. Electrical-prospecting method for hydrocarbon search using the induced-polarization effect. Geophysics, 71: G179-G189.

DIAS CA. 1972. Analytical model for a polarizable medium at radio and lower frequencies. Journal of Geophysical Research, 77: 4945-4956.
DIAS CA. 2000. Developments in a model to describe low-frequency electrical polarization of rocks. Geophysics, 65: 437-451.

DIAS CA, LIMA OAL, SATO HK \& MORAES JAC. 2007. Hydrocarbon detection and reservoir imaging during enhanced oil recovery using an inductive EM multi-frequency method. In: $10^{\text {th }}$ International Congress of SBGf. Expanded Abstract. Rio de Janeiro, RJ, Brazil. CD-ROM.

DIAS CA, LIMA OAL \& SATO HK. 2012. Avaliação do uso do método eletromagnético a multifrequência na exploração e no monitoramento de reservatórios de hidrocarbonetos. Boletim de Geociências da PETROBRAS, 20(1/2): 165-192.

DUKHIN SS \& SHILOV VN. 1974. Dielectric phenomena and the double layer in disperse systems and polyelectrolytes. Israel Program for Scientific Translations, John Wiley \& Sons Inc., New York. 192 pp.

EDWARDS LS. 1977. A modified pseudo-section for resistivity and IP. Geophysics, 42: 1020-1036.

FIGUEIREDO AMF, BRAGA JAE, ZABALAGA JC, OLIVEIRA JJ, AGUIAR GA, SILVA OB, MATO LF, DANILE LMF, MAGNAVITA LP \& BRUHN CHL. 1994. Recôncavo Basin, Brazil: A prolific intracontinental rift basin. In: LANDON SM (Ed.). Interior Rift Basins. American Association of Petroleum Geologists, Spec. Pub., 59: 157-203.

GEOTOMO. 2010. RES2DINV ver. 3.59 for Windows XP/Vista/7. Rapid 2-D Resistivity \& IP inversion using the least-squares method: Geotomo Software, Penang, Malaysia. 148 pp.

HOHMANN GW. 1973. Electromagnetic coupling between grounded wires at the surface of a two-layer Earth. Geophysics, 38: 854-863.

ISHAI PB, TALARY MS, CADUFF A, LEVY E \& FELDMAN Y. 2013. Electrode polarization in dielectric measurements: A review. Measurements Science and Technology, 24: 102-113.

JOHNSON IM. 1990. Spectral IP parameters derived from time-domain measurements. In: FINK JB, McALISTER EO, STERNBERG BK, WIEDUWILT WG \& WARD SH (Eds.). Induced Polarization: Applications and case histories. Society of Exploration Geophysics. USA. Investigations in Geophysics, 4: 57-78.

KELLER GV, PRITCHARD JI, JACOBSON JJ \& HERTHILL N. 1984. Megasource time-domain electromagnetic sounding methods. Geophysics, 49: 993-1009.

KEMNA AA, BINLEY A \& SLATER LD. 2004. Crosshole IP imaging for engineering and environmental application. Geophysics, 69: 97-107.

KETZER JM. 2002. Diagenesis and Sequence Stratigraphy. An Integrated Approach to Constrain Evolution of Reservoir Quality in Sandstones. Acta Universitatis Upsaliensis. Uppsala, Sweden. Comprehensive Summaries of Uppsala Dissertations from the Faculty of Science and Technology, 762, $30 \mathrm{pp}$. 
LESMES DP \& FRYE KM. 2001. Influence of pore fluid chemistry on the complex conductivity and induced polarization response of Berea sandstone. Journal of Geophysical Research, 106: 4079-4090.

LIMA OAL \& SHARMA MM. 1992. A generalized Maxwell-Wagner theory for membrane polarization in shaly sands. Geophysics, 57: 431-440.

LOKE MH. 2015. Tutorial: 2-D and 3-D electrical image surveys. Geotomo Software, Penang, Malaysia.

LOKE MH \& BARKER RD. 1996. Practical techiniques for 2D resistivity surveys and data inversion. Geophysical Prospecting, 44: 499-523.

LUCIA FJ. 2004. Origin and petrophysical of dolostone pore space. Geological Society of London, Special Publication, 235: 141-155.

MADDEN TR \& CANTWELL T. 1967. Induced polarization, A review. Society of Exploration Geophysicist, Mining Geophysics, Vol. II, 373-409.

MARSHALL DJ \& MADDEN TR. 1959. Induced polarization, a study of its causes. Geophysics, 24: 790-816.

MILANI EJ \& DAVISON I. 1988. Basement control and transfer tectonics in the Recôncavo-Tucano-Jatobá rift, Northeast Brazil. Tectonophysics, 154: 41-70.

MILLETT FB. 1967. Electromagnetic coupling of collinear dipoles on a uniform half-space. Part E. Society of Exploration Geophysicists, Mining Geophysics, Vol. II. p. 401-420.

MOCITAIBA LSR, SAMPAIO EES \& LIMA OAL. 2017. Effect of coupling noise on the interpretation of results of electromagnetic horizontal sounding and modeling. Stud. Geophys. Geod., 61: 801-825.

MORAD S, KETZER JM \& DE ROS LF. 2000. Spatial and temporal distribution of diagenetic alterations in siliciclastic rocks: Implications for mass transfer in sedimentary basins. Sedimentology, 47: 95-120.

PALACKY GJ. 1987. Resistivity Characteristics of Geologic Targets. In: NABIGHIAN MN (Ed.). Electromagnetic Methods in Applied Geophysics: Investigations in Geophysics. Society of Exploration Geophysicists, OK, USA. v. 1. p. 52-129.

PELTON WH \& SMITH PK. 1976. Mapping porphyry copper deposits in the Philippines with IP. Geophysics, 41: 106-122.

PELTON WH, WARD SH, HALLOF PG, SILL WR \& NELSON PH. 1978. Mineral discrimination and removal of inductive coupling with multi-frequency IP. Geophysics, 43: 588-609.

REVIL A. 1999. Ionic diffusivity, electrical conductivity, membrane and thermoelectric potentials in colloids and granular porous media: A unified model. Journal of Colloid and Interface Science, 212: 503-522.

SCOTT JBT \& BARKER RD. 2003. Determining pore-throat size in Permo-Triassic sandstones from low-frequency electrical spectroscopy. Geophysical Research Letters, 30: 1450-1456.
SEIGEL HO. 1959. Mathematical formulation and type curves for induced polarization. Geophysics, 24: 547-565.

SLATER L, NTARLAGIANNIS D \& WISHART D. 2006. On the relationship between induced polarization and surface area in metal-sand and clay-sand mixtures. Geophysics, 71: A1-A5.

SILVA OB, CAIXETA JM, MILHOMEM OS \& KOSIN MD. 2007. Bacia do Recôncavo. In: MILANI EJ (Ed.). Bacias Sedimentares Brasileiras - Cartas Estratigráficas. Boletim de Geociências da Petrobras, 15: 423-431.

SPIES B. 1983. Recent developments in the use of surface electrical methods for oil and gas exploration in the Soviet Union. Geophysics, 48: 1102-1112.

STERNBERG BK. 1991. A review of some experience with induced polarization/resistivity method for hydrocarbon survey: Successes and limitations. Geophysics, 56: 1522-1532.

STREICH R, BECKEN M, MATZANDER U \& RITTER 0. 2011. Strategies for land-based controlled-source electromagnetic surveying in high-noise regions. The Leading Edge, 30: 1174-1181.

SUMI F. 1961. The induced polarization method in ore investigation. Geophysical Prospecting, 9: 459-477.

SURDAM RC, CROSSEY LJ, HAGEN ES \& HEOSLER HP. 1989. Organic-inorganic interactions and sandstone diagenesis. Bulletin American Association of Petroleum Geologists, 73: 1-23.

VACQUIER VCR, HOLMES P, KINTZINGER $R$ \& LAVERGNE $M$. 1957. Prospecting for groundwater by induced electric polarization. Geophysics, 22: 660-687.

VINEGAR HJ \& WAXMAN MH. 1984. Induced polarization of shaly sands. Geophysics, 49: 1267-1287.

WAIT JR. 1959. Overvoltage Research and Geophysical Applications. Pergamon Press Inc., New York. 166 pp.

WAIT JR. 1984. Relaxation phenomena and induced polarization. Geoexploration, 22: 107-127.

WAIT JR \& GRUSZKA TP. 1986. On electromagnetic coupling "removal" from induced polarization surveys. Geoexploration, 24: 21-27.

WONG J. 1979. An electrochemical model of the induced-polarization phenomenon in disseminated sulfide ores. Geophysics, 44: 1245-1265.

ZHANGXIANG H, WENBO J \& PINGSHENG L. 2005. Hydrocarbon detection with high-power spectral induced polarization, two cases. In: 75th Annual Meeting. SEG. Houston, Texas, USA. Expanded Abstract. CD-ROM.

ZHANGXIANG H, HAIYING L \& BIYAN T. 2007. Geo-electrical anomaly pattern of reservoir and geo-electrical methods for direct reservoir detection. In: 77th Annual Meeting. SEG, San Antonio, Texas, USA, Expanded Abstract. CD-ROM. 
ZHANGXIANG H, WENBO J \& WEIBING D. 2010. Petroleum electromagnetic prospecting advances and case studies in China. Survey in Geophysics, 31: 207-224.

ZHDANOV MS. 2010. Electromagnetic geophysics: Notes from the past and the road ahead. Geophysics, 75: 75A49-75A66.

ZONGE KL \& WYNN JC. 1975. Recent advances and application in complex resistivity measurements. Geophysics, 40: 851-864.

Recebido em 21 de outubro de 2019 / Aceito em 3 de janeiro de 2020

Received on October 21, 2019 / Accepted on January 3, 2020 